\title{
Transgenic Mice Expressing Human $\alpha$-Synuclein in Noradrenergic Neurons Develop Locus Coeruleus Pathology and Nonmotor Features of Parkinson's Disease
}

\author{
Laura M. Butkovich, ${ }^{1}$ Madelyn C. Houser, ${ }^{1}$ Termpanit Chalermpalanupap, ${ }^{1,3}$ Kirsten A. Porter-Stransky, ${ }^{3,4}$ \\ Alexa F. Iannitelli, ${ }^{3}$ Jake S. Boles, ${ }^{5}{ }^{\circledR}$ Grace M. Lloyd, ${ }^{5}$ Alexandra S. Coomes, ${ }^{5}$ Lori N. Eidson, ${ }^{2}$ \\ ${ }^{\circ}$ Maria Elizabeth De Sousa Rodrigues, ${ }^{1}$ Danielle L. Oliver, ${ }^{1}$ Sean D. Kelly, ${ }^{1}{ }^{5}$ Jianjun Chang, ${ }^{1}$ \\ Nora Bengoa-Vergniory, ${ }^{6}$ Richard Wade-Martins, ${ }^{6}$ Benoit I. Giasson, ${ }^{5}$ Valerie Joers, ${ }^{5}$ David Weinshenker, ${ }^{3}$ and \\ ${ }^{\circ}$ Malú Gámez Tansey ${ }^{5,7}$ \\ ${ }^{1}$ Laney Graduate School, Emory University, Atlanta, Georgia 30322, ${ }^{2}$ Department of Physiology, Emory School of Medicine, Atlanta, Georgia 30322, \\ ${ }^{3}$ Department of Human Genetics, Emory School of Medicine, Atlanta, Georgia 30322, ${ }^{4}$ Department of Biomedical Sciences, Homer Stryker M.D. \\ School of Medicine, Western Michigan University, Kalamazoo, Michigan 49008, ${ }^{5}$ Department of Neuroscience and Center for Translational \\ Research in Neurodegenerative Disease, College of Medicine, University of Florida, Gainesville, Florida 32610, ${ }^{6}$ Oxford Parkinson's Disease Centre, \\ Department of Physiology, Anatomy and Genetics, University of Oxford, Oxford OX1 3QX, United Kingdom, and ${ }^{7}$ Susan and Normal Fixel Chair in \\ Parkinson's Disease, Normal Fixel Institute for Neurological Diseases, University of Florida Health, Gainesville, Florida 32610
}

Degeneration of locus coeruleus (LC) neurons and dysregulation of noradrenergic signaling are ubiquitous features of Parkinson's disease (PD). The LC is among the first brain regions affected by $\alpha$-synuclein (asyn) pathology, yet how asyn affects these neurons remains unclear. LC-derived norepinephrine (NE) can stimulate neuroprotective mechanisms and modulate immune cells, while dysregulation of NE neurotransmission may exacerbate disease progression, particularly nonmotor symptoms, and contribute to the chronic neuroinflammation associated with PD pathology. Although transgenic mice overexpressing asyn have previously been developed, transgene expression is usually driven by pan-neuronal promoters and thus has not been selectively targeted to LC neurons. Here we report a novel transgenic mouse expressing human wild-type asyn under control of the noradrenergic-specific dopamine $\beta$-hydroxylase promoter (DBH-hSNCA). These mice developed oligomeric and conformation-specific asyn in LC neurons, alterations in hippocampal and LC microglial abundance, upregulated GFAP expression, degeneration of LC fibers, decreased striatal DA metabolism, and age-dependent behaviors reminiscent of nonmotor symptoms of PD that were rescued by adrenergic receptor antagonists. These mice provide novel insights into how asyn pathology affects LC neurons and how central noradrenergic dysfunction may contribute to early PD pathophysiology.

Key words: $\alpha$-synuclein; aging; locus coeruleus; nonmotor; norepinephrine; Parkinson's disease

Significance Statement

a-Synuclein (asyn) pathology and loss of neurons in the locus coeruleus (LC) are two of the most ubiquitous neuropathologic features of Parkinson's disease (PD). Dysregulated norepinephrine (NE) neurotransmission is associated with the nonmotor symptoms of PD, including sleep disturbances, emotional changes such as anxiety and depression, and cognitive decline. Importantly, the loss of central NE may contribute to the chronic inflammation in, and progression of, PD. We have generated a novel transgenic mouse expressing human asyn in LC neurons to investigate how increased asyn expression affects the function of the central noradrenergic transmission and associated behaviors. We report cytotoxic effects of oligomeric and conformation-specific asyn, astrogliosis, LC fiber degeneration, disruptions in striatal dopamine metabolism, and age-dependent alterations in nonmotor behaviors without inclusions.

Received June 23, 2019; revised Aug. 2, 2020; accepted Aug. 9, 2020.

Author contributions: L.M.B., T.C., A.F.I., J.S.B., G.M.L., A.S.C., V.J., D.W., and M.G.T. designed research; L.M.B., M.C.H., T.C., K.A.P.-S., A.F.I., J.S.B., G.M.L., A.S.C., L.N.E., M.E.D.S.R., D.L.O., S.D.K., J.C., N.B.-V., and V.J. performed research; G.M.L., R.W.-M., B.I.G., and D.W. contributed unpublished reagents/analytic tools; L.M.B., M.C.H., T.C., K.A.P.-S., A.F.I., J.S.B., G.M.L., A.S.C., L.N.E., M.E.D.S.R., D.L.O., S.D.K., J.C., N.B.-V., B.I.G., V.J., and M.G.T. analyzed data; L.M.B., V.J., and M.G.T. wrote the paper.

\section{Introduction}

Brain regions affected in Parkinson's disease (PD) exhibit proteinaceous aggregates (known as Lewy bodies) primarily composed of $\alpha$-synuclein (asyn), chronic inflammation, and neuron loss (den Hartog and Bethlem, 1960; Spillantini et al., 1997; 
Tansey and Goldberg, 2010). In addition to deficiencies in striatal dopamine (DA) and the DA transporter (DAT), acetylcholine, serotonin, and norepinephrine (NE) systems are also affected (Gonera et al., 1997; Abbott et al., 2005; Ross et al., 2008).

The locus coeruleus (LC) is among the first brain regions affected in PD. The LC is a bilateral pontine nucleus at the lateral floor of the fourth ventricle and is the main source of NE for the CNS (Iversen et al., 1983; Mann et al., 1983; Braak et al., 2001). Asyn aggregates and neuronal degeneration in the LC are ubiquitous features of PD and are associated with nonmotor symptoms including sleep disorders, mood disturbances, and cognitive deficits (Iversen et al., 1983; Chui et al., 1986; German et al., 1992; Braak et al., 2001; Zarow et al., 2003; Weinshenker, 2018). Imaging and histologic studies show a progressive loss of central $\mathrm{NE}$ and noradrenergic neurons, and the accumulation of asyn pathology in the LC in PD (Halliday et al., 1990; German et al., 1992; Brunnström et al., 2011; Pifl et al., 2012; Keren et al., 2015), which may exacerbate the degeneration of DA neurons in the midbrain substantia nigra pars compacta (SNpc; Zarow et al., 2003; Chen et al., 2014).

Depleting LC-NE exacerbates 6-hydroxydopamine- or 1methyl-4-phenyl-1,2,3,6-tetrahydropyridine-induced nigrostriatal pathology in rodents and primates (Mavridis et al., 1991; Srinivasan and Schmidt, 2003; Rommelfanger et al., 2007), while increasing extracellular NE is protective (Kilbourn et al., 1998; Rommelfanger et al., 2004; Kreiner et al., 2019). Furthermore, lesioning LC neurons induces inflammation, and dysregulated NE neurotransmission may contribute to the chronic inflammation seen in PD (Kim and Joh, 2006; Tansey and Goldberg, 2010; Yao et al., 2015; Bharani et al., 2017; Song et al., 2019).

The initiating event in asyn aggregation in sporadic PD is unclear, but candidate mechanisms include increased expression of asyn, as individuals with a multiplication mutation in the gene encoding asyn (SNCA) develop autosomal dominantly inherited PD (Singleton et al., 2003; Chartier-Harlin et al., 2004; Ferese et al., 2015). Age is the primary risk factor for PD, and rodent models of asyn overexpression develop age-dependent asyn aggregates and PD-like behavioral abnormalities (Masliah et al., 2000; Giasson et al., 2002; Hansen et al., 2013). However, in most of these models, transgene expression is driven by a pan-neuronal promoter with asyn overexpression in multiple regions of the CNS, with only one model reporting LC pathology (Masliah et al., 2000; Giasson et al., 2002; Maskri et al., 2004; Schell et al., 2009; Koprich et al., 2010; Sotiriou et al., 2010; Delenclos et al.,

This work was supported by National Institutes of Health (NIH)/National Institute of Neurological Disorders and Stroke (NINDS) Grant 5F31-NS-098673 (L.M.B.), NIH/NINDS Grant F32-NS-098615 (K.A.P.-S.), NIH/NINDS Grant 1R01-NS-102306 (D.W.), NIH/National Institute on Aging (NIA) Grant 1RF1-AG-047667 (D.W.), NIH/NIA Grant 1R01-AG-061175 (D.W.), NIH/NINDS Grant 1R01-NS-100876 (B.I.G.), NIH/NIA Grant 1R01-AG-057247 (M.G.T.), NIH/NINDS Grant 5R01-NS-092122 (M.G.T.), NIH/NIA Grant 3RF1-AG-051514-01 (M.G.T.), and the Norman Fixel Institute for Neurological Diseases (M.G.T.). This research project was also supported in part by the Emory University Integrated Cellular Imaging Microscopy Core, and by the Rodent Behavioral Core (RBC), which is subsidized by the Emory University School of Medicine and is one of the Emory Integrated Core Facilities. Additional support was provided by the Emory Neuroscience NINDS Core Facilities Grant P30-NS055077. Further support was provided by the Georgia Clinical \& Translational Science Alliance of the National Institutes of Health under Award Number UL1-TR-002378. In addition, this study was supported in part by the Emory HPLC Bioanalytical Core, which was supported by the Department of Pharmacology, Emory University School of Medicine and the Georgia Clinical \& Translational Science Alliance of the National Institutes of Health under Award Number UL1-TR-002378. The content is solely the responsibility of the authors and does not necessarily reflect the official views of the National Institutes of Health. Figure 11 was created with https://biorender.com. We thank Terina Martinez, Tim Sampson, and the Tansey, Weinshenker, and Giasson laboratories for useful discussions.

Correspondence should be addressed to Malú Gámez Tansey at mgtansey@ufl.edu.

https://doi.org/10.1523/JNEUROSCI.1468-19.2020

Copyright $\odot 2020$ the authors
2017). Viral-mediated expression has been used to target asyn overexpression to specific brain regions (Baekelandt et al., 2002; Kirik et al., 2002; Delenclos et al., 2017; Ip et al., 2017; Niu et al., 2018). Notably, viral overexpression of a familial PD mutant asyn in LC neurons resulted in asyn aggregation, inflammation, and degeneration of LC neurons (Henrich et al., 2018).

To investigate specifically how pathology induced by increases in asyn affects noradrenergic neurons in the LC in an aging organism, we targeted expression of human wild-type asyn to LC neurons under control of the noradrenergic/adrenergic-specific dopamine $\beta$-hydroxylase (DBH) promoter using bacterial artificial chromosome (BAC) transgenesis. To determine the molecular, cellular, and behavioral age-dependent consequences of increased asyn expression in LC neurons, 3-, 14-, and 24-month-old DBH-hSNCA transgenic $(\mathrm{Tg})$ mice and nontransgenic (nTg) littermate controls were examined.

\section{Materials and Methods}

Experimental design. To determine how the expression of human asyn in LC neurons affects neuronal health and LC-NE-associated behaviors, mice were aged undisturbed until the time of behavioral testing or killing at ages 3,14 , and 24 months.

Generation of the DBH-hSNCA mouse model. Male and female mice expressing human wild-type $\alpha$-synuclein $(D B H-h S N C A)$ were engineered using a commercially available human BAC RP11-746P3 (Cubells et al., 2016) encompassing the $D B H$ gene. The wild-type $h S N C A$ cDNA open reading frame ( $400 \mathrm{bp}$ ) was targeted to the translational start site of $D B H$ by standard BAC recombineering methods by the University of North Carolina at Chapel Hill Molecular Neuroscience Core (currently the UNC Animal Models Core). The BAC construct was injected into $\mathrm{C} 57 \mathrm{BL} / 6 \mathrm{~N}$ pronuclei by the Emory University Mouse Transgenic and Gene Targeting Core facility (http://www.cores.emory. edu/tmc/index.html), transgene expression in founder pups was determined by PCR, and breeding lines were established. Mice carrying the hSNCA sequence were crossed with wild-type C57BL/6N mice (Charles River Laboratories) to establish the hemizygous transgenic DBH-hSNCA line.

To improve the efficiency and accuracy of LC tissue isolation for Western blot and mRNA analysis, DBH-hSNCA mice were crossed with the TH-EGFP reporter mouse expressing enhanced green fluorescent protein (EGFP) under the tyrosine hydroxylase (TH) promotor (Sawamoto et al., 2001).

Animals. Male and female DBH-hSNCA mice were maintained on a $\mathrm{C} 57 \mathrm{BL} / 6$ background. Mice were group housed (maximum of five mice per cage) until 2 weeks before the start of behavioral testing, when they were singly housed until killed. Animals were maintained on a $12 \mathrm{~h}$ light/dark cycle with access to standard rodent chow and water ad libitum. Hemizygous animals served as experimental mice, with nontransgenic littermates as controls. Genotypes were determined by tail snip PCR with the following two sets of primers: forward, $5^{\prime}$-TGTCC AAGATGGACCAGACTC-3', reverse, 3'-ACTGGTCTGAGGCAGG GAGCA-5'; and set forward, 5'-GCCCTCAGTCTACTTGCGGGA-3', reverse, $3^{\prime}$-GCGAGAGCATCATAGGGAGT-5'. Experimental procedures involving the use of animals were performed in accordance with the National Institutes of Health Guidelines for the Care and Use of Laboratory Animals and were approved by the Institutional Animal Care and Use Committee at Emory University School of Medicine.

Sleep latency test. Latency to fall asleep was quantified as the duration of time following gentle handling until their first sleep bout, which was defined as sleeping continuously for $2 \mathrm{~min}$, and for a total of $75 \%$ of the 10 min period that began at sleep onset (Hunsley and Palmiter, 2004). Sleep testing began at 9:00 A.M., $2 \mathrm{~h}$ into the light cycle when internal pressure to sleep is high. The sessions were video recorded and scored by an experienced observer blind to the genotype. We have validated this behavioral sleep scoring method with EEG (Porter-Stransky et al., 2019). 
Marble-burying test. Marble burying is a test of anxiety/compulsivelike behaviors that we have previously shown reflects increased noradrenergic transmission (Lustberg et al., 2020) and was conducted as previously described (de Sousa Rodrigues et al., 2017). Mice were placed in a plastic tub $(50.5 \times 39.4 \times 19.7 \mathrm{~cm})$ containing 5 inches of lightly pressed bedding. Twenty marbles of uniform size and color were placed in five rows of four marbles, each on top of the bedding. Mice were placed in the containers and allowed to roam freely for $30 \mathrm{~min}$. At the end of testing, the mice were placed back into home cages, and the number of marbles buried to at least two-thirds of their height were counted. Marble burying was conducted 2 weeks after sleep latency testing.

Open field testing. In the open field test, a mouse that spends less time in or hesitates to re-enter the open center of the testing chamber is considered to be exhibiting anxiety-like behavior (Britton and Britton, 1981). During the light phase of the light/dark cycle, mice were acclimated to a dark testing room under red light for $1 \mathrm{~h}$ before testing. Mice were placed into the open field (a $45 \times 45 \mathrm{~cm}$ square box) and allowed to move freely for $10 \mathrm{~min}$. Distance, velocity, center, and border statistics were measured using Noldus/Ethovision software. Center was defined as the central $22.5 \times 22.5 \mathrm{~cm}$. Open field testing was conducted 1 week after marble burying.

Circadian locomotion. All testing mice were acclimated to the testing room for $2 \mathrm{~d}$ before the experiment. Mice were each placed in a clear Plexiglas (length, 15.75 inches; width, 13.25 inches; height, 7.38 inches) activity cage equipped with infrared photobeams (San Diego Instruments). Food and water were available ad libitum during the $23 \mathrm{~h}$ testing period. Ambulations (consecutive photobeam breaks) were recorded by PAS software. Circadian locomotion behavior was assessed 2 weeks after open field testing.

Fear conditioning. Fear-conditioning training and contextual and cued fear testing is a test of memory for the association of an aversive stimulus with an environment cue or context, and was conducted as previously described (Chalermpalanupap et al., 2018) over 3 consecutive days. Mice were placed in a fear-conditioning apparatus (width, 7 inches; depth, 7 inches; height, 12 inches; Coulbourn Instruments) with a metal shock grid floor and were allowed to explore the enclosure for $3 \mathrm{~min}$. Following habituation, three conditioned stimulus (CS)-unconditioned stimulus (US) pairings were presented with a $1 \mathrm{~min}$ intertrial interval. The CS was a $20 \mathrm{~s} 85 \mathrm{~dB}$ tone, and the US was a $2 \mathrm{~s} 0.5 \mathrm{~mA}$ footshock (Precision Animal Shocker, Colbourn Instruments), which coterminated with CS presentation. The contextual test was conducted on the following day when animals were placed back into the same chamber. On day 3 , the animals were placed in a novel compartment and allowed to habituate for $2 \mathrm{~min}$. Following habituation, the $85 \mathrm{~dB}$ tone was presented, and the amount of freezing behavior was recorded. No shocks were given during the contextual or cued tests. Fear conditioning was conducted 1 week after circadian locomotion behavior.

Behavioral pharmacology. For the 3 days before pharmacological experiments, mice received vehicle administration to habituate them to intraperitoneal injections. On the day of testing, mice received vehicle or a cocktail of the $\alpha 1$-adrenergic receptor antagonist prazosin $(0.5 \mathrm{mg} / \mathrm{kg}$; Sigma-Aldrich) and the $\beta$-adrenergic receptor antagonist DL-propranolol (5 mg/kg; Sigma-Aldrich), immediately before sleep latency testing. Drug doses were chosen based on previous studies and optimized in pilot experiments to ensure that behavioral effects were not because of sedation (Vazey and Aston-Jones, 2014). Treatments were counterbalanced between subjects, and all mice received vehicle or a drug cocktail with a $7 \mathrm{~d}$ washout period between testing days.

Tissue collection. Animals used in immunohistochemical and HPLC analyses were anesthetized by injection of sodium pentobarbital (Euthasol, Virbac) until unresponsive. Mice were transcardially perfused with PBS, pH 7.4, until exiting blood ran clear. Brain tissue was removed, with one hemisphere postfixed in $4 \%$ paraformaldehyde (PFA) for immunohistochemistry, and the other dissected and flash frozen for HPLC. Animals used for quantitative PCR (qPCR) or Western blot analyses were killed by cervical dislocation under isoflurane anesthesia. Tissue was flash frozen and stored at $-80^{\circ} \mathrm{C}$ until processing.

Immunofluorescence and analysis. Brain tissue was sectioned on a freezing microtome (model SM2010R, Leica) at $40 \mu \mathrm{m}$ and stored in cryoprotectant (30\% ethylene glycol, $30 \%$ sucrose, $13.32 \mathrm{~mm} \mathrm{NaH}_{2} \mathrm{PO}_{4}$, $38.74 \mathrm{~mm} \mathrm{Na}_{2} \mathrm{HPO}_{4}, 250 \mu \mathrm{M}$ polyvinylpyrrolidone) solution at $-20^{\circ} \mathrm{C}$ until staining. Sections were washed in PBS before blocking in 5\% normal goat serum (NGS; catalog \#005-000-121, Jackson ImmunoResearch) with $0.05 \%$ Triton X-100 (catalog \#T9284100, Sigma-Aldrich) in Trisbuffered saline (TBS), $\mathrm{pH}$ 7.4, for $1 \mathrm{~h}$ at room temperature (RT). Sections were transferred directly to primary antibody solution containing $1 \%$ NGS, $0.05 \%$ Triton X-100, and antibody at the concentrations described in Table 1 and incubated overnight at RT [05-02 Ms anti-NET (norepinephrine transporter)]. Fluorescently conjugated secondary antibodies (described in Table 1) were diluted in $0.1 \%$ NGS with $0.05 \%$ Triton X-100, and tissue sections were incubated for $1 \mathrm{~h}$ at RT in the dark. Sections were mounted on Superfrost Plus slides (VWR) and were coverslipped with Vectashield with DAPI (Vector Laboratories). All immunofluorescent images were acquired as $z$-stack images, and the file was compressed on a Keyence BZ-X700 microscope system. The Allen Brain Atlas version 1 (2008) was used to identify regions of interest (ROIs). One section per mouse containing the dorsal hippocampus (near bregma $-1.995 \mathrm{~mm}$ ) and one containing the LC (bregma $-5.555 \mathrm{~mm}$ ) were analyzed for the percentage of immunoreactivity (IR) within a standard ROI. A detection threshold was set uniformly across images in each analysis, and the percentage of IR was determined using the "Measure" feature of ImageJ. The percentage of IR was calculated as the area of IR within the ROI divided by the total ROI area and multiplied by 100. Quantification of Iba1-positive cells (microglia) was also analyzed with a standard threshold, ROI, and upper and lower size limits using the "Analyze particles" function in ImageJ.

Immunohistochemistry and analysis. For immunoperoxidase visualization of phosphorylation at serine 129 (pSer129) asyn (Rutherford et al., 2016) and conformation-specific asyn, brains were postfixed with $4 \%$ paraformaldehyde, incubated in $70 \%$ ethanol, and then embedded in paraffin. Paraffin sections were cut at $5 \mu \mathrm{m}$ and stained using previously published protocols (Joers et al., 2014; Lloyd et al., 2020). Briefly, sections were deparaffinized and rehydrated, and heat-induced antigen retrieval was performed using $10 \mathrm{~mm}$ sodium citrate solution, $\mathrm{pH} 6.0$ (pSer129), or citrate Target Retrieval Solution (catalog \#S169984-2, Dako), pH 6.1, with 0.05\% Tween-20 (conformation specific) for $30 \mathrm{~min}$. Next, endogenous peroxidase was blocked, and nonspecific binding sites minimized with $8 \%$ serum (Jackson ImmunoResearch), 20\% avidin/biotin blocking solution (catalog \#SP-2001, Vector Laboratories), and 0.1\% Triton X-100 in TBS for $1 \mathrm{~h}$ (pSer129), or 2\% FBS in $0.1 \mathrm{~m}$ Tris, pH 7.6, for $10 \mathrm{~min}$ (conformation-specific). Sections were transferred into primary antibody solution containing 5\% serum and $20 \%$ avidin/biotin blocking solution (catalog \#SP-2001, Vector Laboratories) in TBS (pSer129) or 2\% FBS in $0.1 \mathrm{~m}$ Tris (conformation specific) and antibody concentrations were detailed in Table 1 overnight at $4^{\circ} \mathrm{C}$. The sections were then incubated in appropriate biotinylated secondary antibodies diluted with $5 \%$ serum in TBS (pSer129) for $30 \mathrm{~min}$ or $2 \%$ FBS in $0.1 \mathrm{M}$ Tris for $1 \mathrm{~h}$ (conformation specific) at room temperature. The antigen signal was amplified using the VectaStain ABC-HRP Elite Kit (catalog \#PK-6100, Vector Laboratories) for $1 \mathrm{~h}$ at room temperature, and staining was developed using diaminobenzine (DAB) as the chromogen (catalog \#D4293, Sigma-Aldrich). Sections were counterstained with Mayer's hematoxylin (catalog \#51275, Sigma-Aldrich). Sections stained for conformation-specific asyn underwent additional blocking with $2 \%$ FBS in $0.1 \mathrm{M}$ Tris before secondary antibody and DAB incubations. All DAB-immunostained slides were imaged with a Leica microscope (DMi8 Thunder) and postprocessed through Adobe Photoshop to improve contrast. The intensity of conformation-specific asyn-IR in the LC was scored by experimenters blinded to genotype using the following rubric: $0=$ no staining in the LC; $1=<25 \%$ of the LC stained; $2=25-$ $50 \%$ of the LC stained; $3=>50 \%$ of the LC stained. Images for pSer 129 asyn were not quantified.

Proximity ligation assay. An asyn proximity ligation assay (PLA) was performed to detect oligomeric species as previously described (Roberts et al., 2015; Bengoa-Vergniory et al., 2017). Paraffin-embedded tissue was rehydrated by consecutive incubations in xylene, Histoclear, $100 \%$ 
Table 1. Primary and secondary antibodies used in these studies

\begin{tabular}{|c|c|c|c|c|}
\hline Immunofluorescence & Host & Manufacturer & Catalog \# & Dilution \\
\hline \multicolumn{5}{|l|}{ Antigen } \\
\hline$\alpha$-Synuclein (Hu) & Mouse & BioLegend & 807801 & $1: 500$ \\
\hline DAT & Rat & Millipore & MAB369 & $1: 500$ \\
\hline GFAP & Rabbit & Zymed & $13-0300$ & 1:500 \\
\hline lba1 & Rabbit & Wako & 019-19741 & $1: 500$ \\
\hline NET & Mouse & MAB Technologies & NET05-2 & $1: 1000$ \\
\hline Tyrosine hydroxylase & Rabbit & Millipore & AB152 & $1: 1000$ \\
\hline Tyrosine hydroxylase & Chicken & Abcam & AB76442 & $1: 1000$ \\
\hline Anti-chicken Alexa Fluor 488 & Goat & Thermo Fisher Scientific & A11039 & $1: 1000$ \\
\hline Anti-rabbit Alexa Fluor 488 & Goat & Thermo Fisher Scientific & A11015 & 1:1000 \\
\hline Anti-mouse Alexa Fluor 594 & Goat & Thermo Fisher Scientific & A11020 & $1: 1000$ \\
\hline Anti-rabbit Alexa Fluor 594 & Goat & Thermo Fisher Scientific & A11012 & $1: 1000$ \\
\hline Anti-rat Alexa Fluor 594 & Goat & Thermo Fisher Scientific & A11007 & $1: 1000$ \\
\hline \multicolumn{5}{|l|}{ Proximity ligation assay } \\
\hline$\alpha$-Synuclein (Hu) & Mouse & Abcam & AB80627 & $1: 1000$ \\
\hline$\alpha$-Synuclein- pSer129 & Mouse & BioLegend & MMS-5091 & $1: 1000$ \\
\hline Syn-F1 & Mouse & BioLegend & 847802 & $1: 1000$ \\
\hline \multicolumn{5}{|l|}{ Immunoblotting } \\
\hline$\alpha$-Synuclein (Hu) & Mouse & Abcam & AB80627 & $1: 1000$ \\
\hline$\alpha$-Synuclein (Ms $+\mathrm{Hu})$ & Rabbit & Santa Cruz Biotechnology & SC-7011R & $1: 500$ \\
\hline Tyrosine hydroxylase & Rabbit & Millipore & AB152 & $1: 1000$ \\
\hline Anti-mouse HRP & Goat & Jackson ImmunoResearch & $115-036-072$ & $1: 1000$ \\
\hline Anti-rabbit HRP & Goat & Jackson ImmunoResearch & $111-036-047$ & $1: 1000$ \\
\hline \multicolumn{5}{|l|}{$\mathrm{IHC}$ and dot blot } \\
\hline$\alpha$-Synuclein-pSer129 (EP1536Y) & Rabbit & Abcam & AB51253 & $1: 2500$ \\
\hline$\alpha$-Synuclein-pSer129 (LS4-2G12) & Mouse & Rutherford et al., 2016 & & $1: 5000$ \\
\hline$\alpha$-Synuclein conformation-specific & Rabbit & Abcam & AB209538 & 1:10,000 (immunohistochemistry) \\
\hline$\alpha$-Synuclein conformation-specific & Rabbit & Abcam & AB209538 & 1:1000 (dot blot) \\
\hline Tyrosine hydroxylase & Rabbit & Millipore & AB152 & $1: 1500$ \\
\hline Biotinylated anti-rabbit & Goat & Vector Laboratories & BA-1000 & $1: 200$ \\
\hline Biotinylated anti-mouse & Horse & Vector Laboratories & BA-2000 & $1: 200$ \\
\hline Anti-rabbit HRP & Goat & Jackson ImmunoResearch & $111-036-047$ & $1: 1000$ \\
\hline
\end{tabular}

ethanol, 95\% ethanol, 70\% ethanol, and $\mathrm{H}_{2} \mathrm{O}$. Samples were then incubated in $10 \% \mathrm{H}_{2} \mathrm{O}_{2}$ in PBS to reduce background and were heated in a microwave in citrate buffer, $\mathrm{pH} 6.0$ (Abcam) for antigen retrieval. After antigen retrieval, samples were processed for immunofluorescence, as follows: $1 \mathrm{~h}$ RT incubation in $10 \%$ serum with $0.05 \%$ Tween- 20 in TBS block, $1 \mathrm{~h}$ incubation in primary antibody, and TBS with $0.05 \%$ Tween20 (TBS-T) wash. Slides were then incubated for $1 \mathrm{~h}$ with secondary antibodies conjugated to Life Technologies Alexa Fluor 488 (Thermo Fisher Scientific) and washed again with TBS-T. For immunohistochemistry, samples were then coverslipped with FluorSave (Calbiochem). For PLA, samples were covered in PLA blocking solution (Sigma-Aldrich) for $1 \mathrm{~h}$ at $37^{\circ} \mathrm{C}$, and then incubated overnight with PLA conjugates (a-syn211; catalog \#ab80627, Abcam). The next day, samples were washed with TBS-T, incubated in ligation solution for $1 \mathrm{~h}$ at $37^{\circ} \mathrm{C}$, washed with TBS$\mathrm{T}$, incubated in amplification solution for $2.5 \mathrm{~h}$ at $37^{\circ} \mathrm{C}$, washed with TBS, counterstained with DAPI, and mounted with FluorSave. All PLA reagents were used per manufacturer instructions (catalog \#92008, Sigma-Aldrich). PLA puncta were counted by experimenters blinded to genotype from 25 cells per LC section per animal. Two independent experimental rounds were normalized and averaged to provide the final quantification.

Dot blots. Frozen LC samples were homogenized in RIPA buffer ( $1 \%$ Triton X-100, 50 mm Tris HCl, 0.1\% SDS, 150 mm NaCL, pH 8.0) or Life Technologies TRIzol (catalog \#15596-018, Thermo Fisher Scientific) and centrifuged at $12,000 \times g$ for $10 \mathrm{~min}$. Supernatants were transferred to fresh tubes and quantified for protein concentration by BCA Assay. Samples were diluted in PBS, and 225 ng was spotted directly onto nitrocellulose membranes (catalog \#1620117, Bio-Rad) for dot blot analysis (Sampson et al., 2016). Membranes were air dried for $10 \mathrm{~min}$ and blocked in TBS-T containing 5\% nonfat dry milk for $1 \mathrm{~h}$. Membranes were probed for conformation-specific asyn (Table 1 ) at $4^{\circ} \mathrm{C}$ overnight with gentle rocking. Membranes were incubated with HRP-conjugated secondary antibodies, followed by SuperSignal West Pico PLUS Chemiluminescent Substrate (Thermo Fisher Scientific) and imaged using a LI-COR (Odyssey FC) system.

RNA scope. In situ RNA analysis was performed using RNAScope Multiplex Fluorescent v2 kit (catalog \#3231000, ACD). Tissue preparation and analysis were conducted as described in the manufacturer protocol. Briefly, following transcardial perfusion with saline, brains were incubated in $4 \%$ PFA for $24 \mathrm{~h}$ followed by a series of increasing sucrose concentrations before being frozen in optimal cutting temperature medium (Sakura) and stored at $-80^{\circ} \mathrm{C}$ until sectioning. Tissue sections $(12 \mu \mathrm{m})$ were collected on a Leica CM1900 cryostat and mounted on Superfrost Plus slides. To prevent tissue detachment, slides were dried at $60^{\circ} \mathrm{C}$ for $30 \mathrm{~min}$ and fixed in $4 \%$ PFA for $15 \mathrm{~min}$ at $4^{\circ} \mathrm{C}$ before ethanol dehydration. Tissue was processed as described in the ACD protocol (acdbio.com/technical-support/user-manuals/\#323100-USM).

Western immunoblotting. Western blots were conducted as previously described (de Sousa Rodrigues et al., 2017). Flash frozen samples were stored at $-80^{\circ} \mathrm{C}$ until processing. Protein was isolated from LC samples with RIPA buffer. RIPA samples were centrifuged at 12,000 rpm for $20 \mathrm{~min}$ at $4^{\circ} \mathrm{C}$. Supernatant was transferred to a new tube for conducting a Pierce Scientific BCA assay (catalog \#23225, Thermo Fisher Scientific). TRIzol samples were resuspended in $1 \%$ SDS. Samples were diluted to $1 \mu \mathrm{g} / \mu \mathrm{l}$ in $4 \times$ sample buffer (catalog \#1610747, Bio-Rad) and boiled at $90^{\circ} \mathrm{C}$ for $5 \mathrm{~min}$. Electrophoresis was performed using $12 \%$ gels (5 $\mu \mathrm{l}$; catalog \#4568046, Bio-Rad) and transferred to $0.45 \mu \mathrm{m}$ PVDF membrane using Trans-Blot Turbo Transfer System (Bio-Rad). For immunoblotting, the membrane was fixed in $0.4 \%$ PFA for 30 min following transfer. After a brief wash, blots were incubated in $5 \%$ milk blocking buffer (Bio-Rad) for $1 \mathrm{~h}$ at $4^{\circ} \mathrm{C}$ before primary antibody overnight at $4^{\circ} \mathrm{C}$ (Table 1$)$. Membranes were washed with TBS-T $(0.01 \%$ 
A

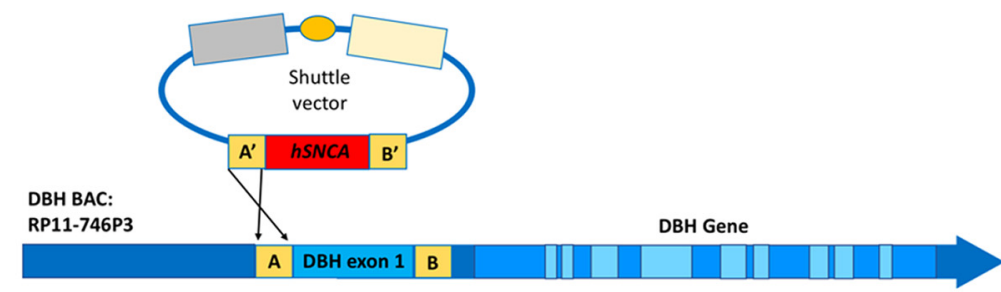

Modified DBH BAC:

DBH-hSNCA
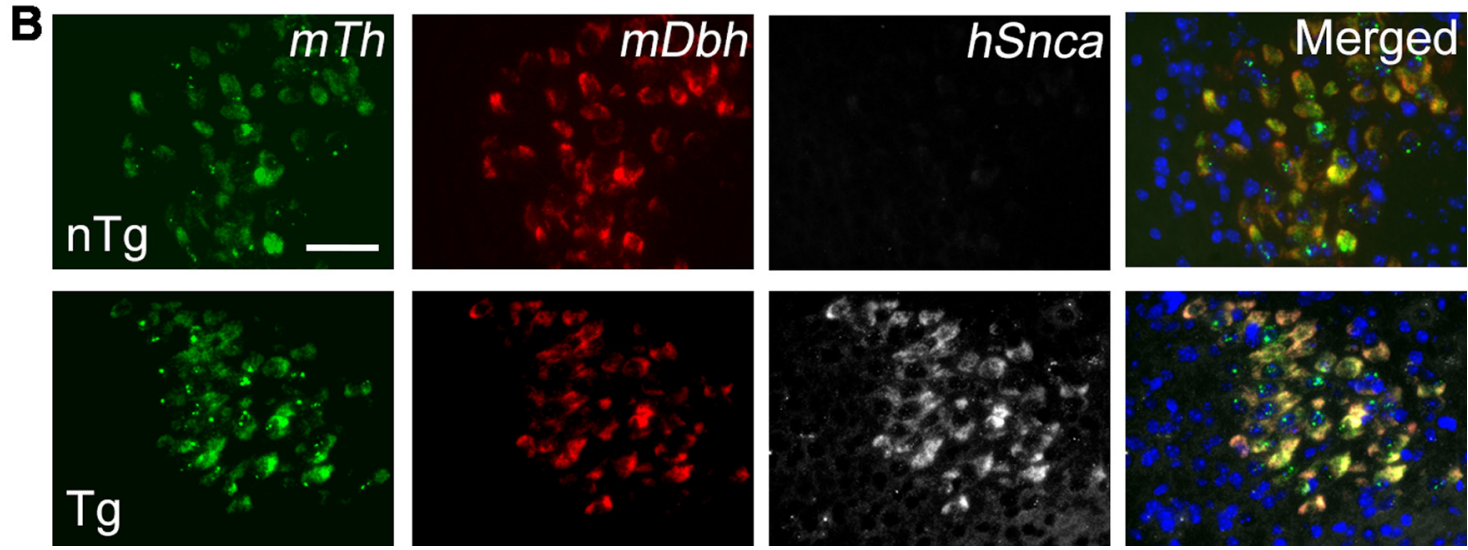

Figure 1. Human Snca mRNA is expressed in DBH-hSNCA locus coeruleus neurons. A, hSNCA cDNA open reading frame was targeted to the translational start site of DBH by standard BAC recombineering methods. $\boldsymbol{B}$, Human Snca mRNA (hSnca; white) expression is detectable only in $\mathrm{Tg}$ (bottom row) $\mathrm{LC}$ neurons, where it colocalizes with mouse $T h \mathrm{mRNA}$ (mTh; green) and mouse Dbh mRNA (mDbh; red) using RNA Scope Fluorescent Multiplex v2 assay. Scale bar, $50 \mu \mathrm{m}$.

Tween-20) and incubated in HRP-conjugated secondary antibodies in blocking buffer for $1 \mathrm{~h}$ at room temperature. Images were acquired using Azure Biosystems and analyzed by ImageStudio Lite software. Protein expression was normalized to total protein (catalog \#926-11015, Li-Cor).

HPLC. Monoamines were examined by HPLC with electrochemical detection, as described previously (Song et al., 2012). For HPLC, an ESA 5600A CoulArray detection system, equipped with an ESA Model 584 pump and an ESA 542 refrigerated autosampler, was used. Separations were performed using an MD-150 × $3.2 \mathrm{~mm} \mathrm{C18}(3 \mu \mathrm{M})$ column at $25^{\circ} \mathrm{C}$. The mobile phase consisted of $8 \%$ acetonitrile, 75 $\mathrm{mm} \mathrm{NaH}_{2} \mathrm{PO}_{4}, 1.7 \mathrm{~mm} 1$-octanesulfonic acid sodium, and $0.025 \%$ trimethylamine at $\mathrm{pH}$ 2.9. Twenty-five microliters of sample were injected. The samples were eluted isocratically at $0.4 \mathrm{ml} / \mathrm{min}$ and detected using a 6210-electrochemical cell (equipped with 5020 guard cell; ESA). Guard cell potential was set at $475 \mathrm{mV}$, while analytical cell potentials were $-175,150,350$, and $425 \mathrm{mV}$. The analytes were identified by the matching criteria of retention time and sensor ratio measures to known standards (Sigma-Aldrich) consisting of dopamine, norepinephrine, 3,4-dihydroxyphenylacetic acid (DOPAC), and 4hydroxy-3-methoxyphenylglycol (MHPG). Compounds were quantified by comparing peak areas to those of standards on the dominant sensor.

Statistical analysis. The Student's $t$ test was used to assess differences by genotype within each age group in sleep latency, marble burying, open field, Western blot, and all immunofluorescent analyses. Repeatedmeasures two-way ANOVA was used to analyze differences by genotype (between-subject) for within-subject conditions including fear-conditioning and circadian locomotor assay followed by Tukey's post hoc test, where applicable. Analyses were conducted within each age group. Comparisons across age groups were not conducted, as behavioral assays, HPLC, and immunofluorescence of each cohort were conducted at separate time points. The analyses were performed using GraphPad Prism 7 (GraphPad Software) with a $p$ value threshold of $<0.05$.

\section{Results}

Generation of $D B H-h S N C A$ mice and expression of human SNCA mRNA in DBH-hSNCA LC neurons

The DBH-hSNCA mouse model was developed using a DBHBAC construct carrying the wild-type human SNCA cDNA open reading frame at the translational start site of $D B H$ (Fig. $1 A$ ). Transgene integration was confirmed by PCR, and founder mice were bred with wild-type C57BL/6 mice to establish the hemizygous $D B H$-hSNCA line. Fluorescent in situ mRNA analysis revealed human Snca mRNA in Tg LC neurons (Fig. 1B), which colocalized with mouse Th and mouse Dbh mRNA, while human Snca mRNA expression was not detected in $\mathrm{nTg}$ LC neurons.

\section{Human asyn is expressed in select noradrenergic brainstem} nuclei of $D B H-h S N C A$ transgenic mice

Human asyn protein in the LC was analyzed by immunofluorescence and Western blot. Using an antibody specific for human asyn (catalog \#807801, BioLegend), the expression of human asyn was found to colocalize with $\mathrm{TH}$-expressing LC neurons only in brain sections from DBH-hSNCA Tg mice (Fig. 2A). No human asyn-specific immunofluorescence was detected in LC neurons of nTg littermates or in SNpc neurons regardless of genotype (Fig. $2 A, C$ ). Human asyn was also detectable specifically in LC protein lysate from Tg tissue by immunoblot and not in nTg lysates (Fig. 2B; $n=4$ ). Quantitative Western blot analysis of LC protein using a pan-asyn antibody to detect both human and mouse asyn protein revealed a significant $\sim 30 \%$ increase of total asyn in Tg mice at 3 months relative to that in $\mathrm{nTg}$ littermates (Fig. $\left.2 D ; t_{(6)}=3.156, p=0.0197, n=4\right)$. Human SNCA mRNA expression in Tg LC neurons was confirmed by qPCR (data not shown). The expression of human asyn was confirmed in the A4 

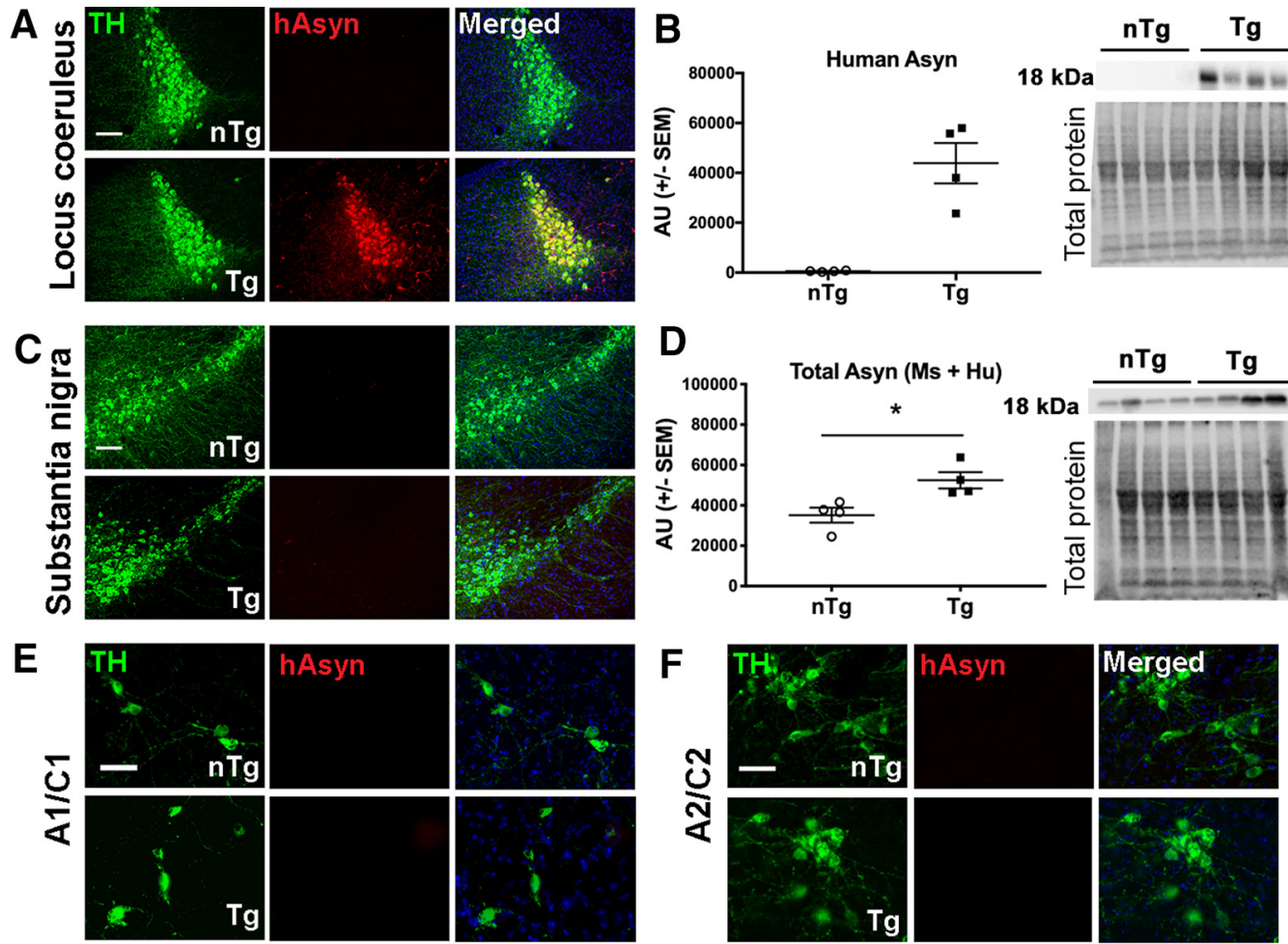

G
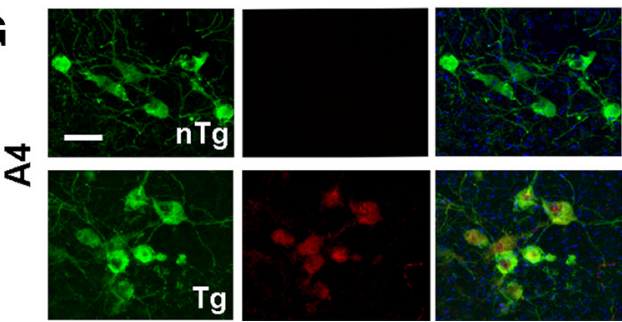
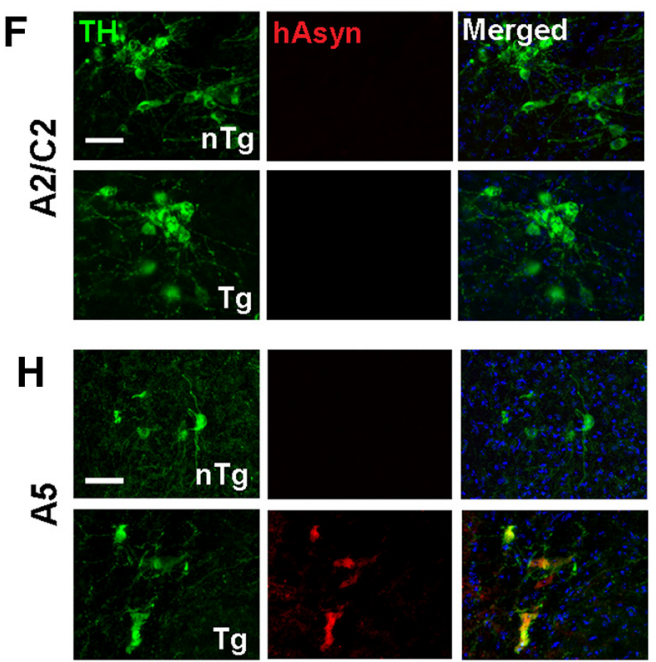

Figure 2. Analysis of asyn expression in catecholaminergic brainstem regions of young DBH-hSNCA mice. $A, C$, Immunofluorescent detection of human asyn (hAsyn; red) with a species-specific antibody (catalog \#807801, BioLegend) demonstrates colocalization with TH-expressing LC neurons (green) in Tg mice (bottom; $\boldsymbol{A}$ ) but not in nTg mice (top) or in TH-expressing neurons (green) in the substantia nigra regardless of genotype (C). $\boldsymbol{B}$. Human asyn protein is expressed selectively in $\mathrm{LC}$ neurons of DBH-hSNCA $\times$ TH-EGFP mice by Western blot. $\boldsymbol{D}$, Immunoblot of $\mathrm{LC}$ protein with an antibody against asyn that detects the mouse and human protein reveals a significant increase in total asyn protein expression in LC neurons of DBH-hSNCA $\times$ TH-EGFP mice compared with that in $\mathrm{LC}$ of nTg littermate mice. Immunoblot data graphed as arbitrary units (AU) normalized to total protein. $\boldsymbol{E}-\boldsymbol{H}$, Human asyn is not expressed in the $\mathrm{A} 1 / \mathrm{C} 1(\boldsymbol{E})$ or the $\mathrm{A} 2 /$ C2 region $(\boldsymbol{F})$, but is detectable in the $\mathrm{A} 4(\boldsymbol{G})$ and $\mathrm{A} 5(\boldsymbol{H})$ regions of Tg mice by immunofluorescence. All data are from 3-month-old $\mathrm{nTg}$ and Tg mice. Scale bars: $\boldsymbol{A}, \boldsymbol{C}, 100 \mu \mathrm{m} ; \boldsymbol{E}-\boldsymbol{H}, 50 \mu \mathrm{m}$. Student's $t$ test \pm SEM, ${ }^{*} p<0.05$.

(Fig. 2G) and A5 (Fig. 2H) DBH-expressing regions in the pons of Tg mice by immunofluorescence, but expression was not detectable in the medullary A1/C1 (Fig. $2 E$ ) or A2/C2 (Fig. $2 F$ ) nuclei of $D B H$ - $h S N C A$ mice.

$D B H-h S N C A$ mice exhibit behavioral phenotypes that resemble features of nonmotor $\mathrm{PD}$ symptoms

A primary role of the LC-NE system is promoting arousal and wakefulness; LC activity is highest just before and during wake (Hobson et al., 1975). Sleep disturbances are one of the most common nonmotor PD symptoms, and PD patients with disturbed sleep have greater asyn pathology in the LC than PD patients without sleep complaints (Kalaitzakis et al., 2013). Thus, sleep latency was assessed to examine whether features of the sleep/wake cycle were affected by human asyn expression in the LC. Mice were gently handled and returned to their home cages, and the video recording was scored by an observer blind to the genotype to determine latency to fall asleep. Our findings indicate that there was a significant increase in sleep latency in $\mathrm{Tg}$ mice at 3 months (Fig. $3 A ; t_{(14)}=4.36 p=0.0007 ; n=8$ ) and at 14 months $\left(t_{(17)}=2.51, p=0.0225 ; n=9 \mathrm{nTg}\right.$ and $\left.n=10 \mathrm{Tg}\right)$, indicative of an elevated arousal state. No differences were observed at 24 months $\left(t_{(8)}=0.821, p=0.4354, n=8 \mathrm{nTg}\right.$ and $\left.n=7 \mathrm{Tg}\right)$.

Central noradrenergic neurons, including the LC and A2 regions, are activated by stress exposure, and blocking LC activity abolishes stress-induced anxiety-like behavior (Rinaman, 2011; McCall et al., 2015). In PD, anxiety severity is inversely correlated with LC function (Remy et al., 2005). To examine anxietylike behavior, the behavior of $D B H-h S N C A$ mice was assessed in marble-burying and open field tests. In the marble-burying assay, there was a significant increase in the number of marbles buried by Tg mice at 14 months (Fig. $3 B ; t_{(18)}=2.735, p=0.0136 ; n=8$ $\mathrm{nTg}$ and $n=12 \mathrm{Tg})$ and 24 months $\left(t_{(13)}=2.212, p=0.0455, n=\right.$ $8 \mathrm{nTg}$ and $n=7 \mathrm{Tg})$, but not at 3 months $\left(t_{(13)}=1.369\right.$, $p=0.1942, n=7 \mathrm{nTg}$ and $n=8 \mathrm{Tg}$ ). In open field tests, an agedependent anxiety-like phenotype was also evident in 14-monthold Tg mice, evinced by an increase in the latency to re-enter the center of the testing field (Fig. $3 C$; $t_{(17)}=2.359, p=0.0305 ; n=7$ $\mathrm{nTg}$ and $n=12 \mathrm{Tg})$, with no differences in 3-month-old $\left(t_{(11)}=\right.$ $0.1988, p=0.8460, n=8 \mathrm{nTg}$ and $n=5 \mathrm{Tg}$ ) or 24-month-old animals $\left(t_{(11)}=0.5075, p=0.6219, n=5 \mathrm{nTg}\right.$ and $\left.n=5 \mathrm{Tg}\right)$. The 
A

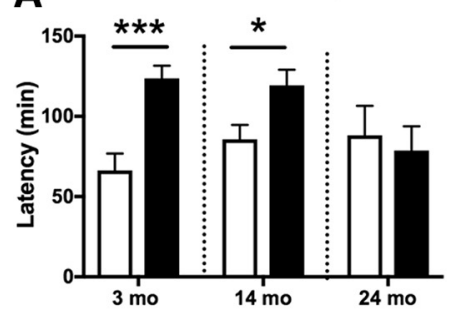

D

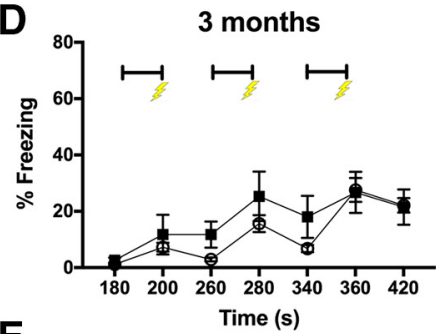

E

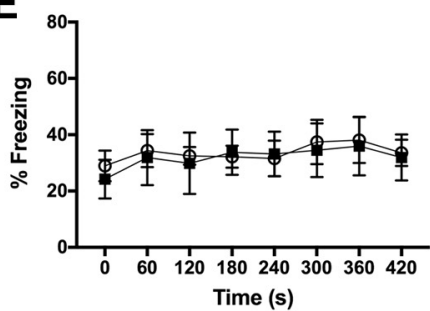

$\mathbf{F}$
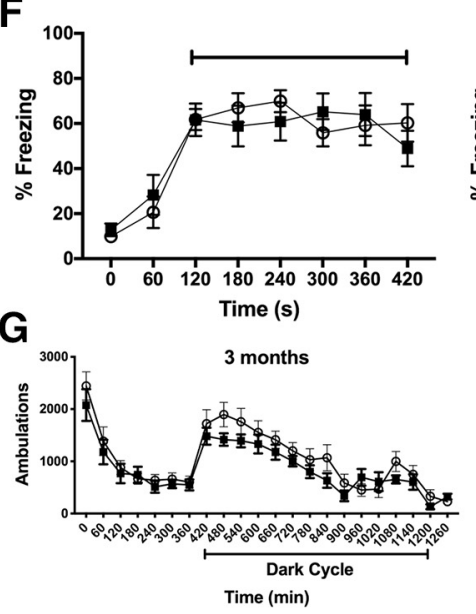
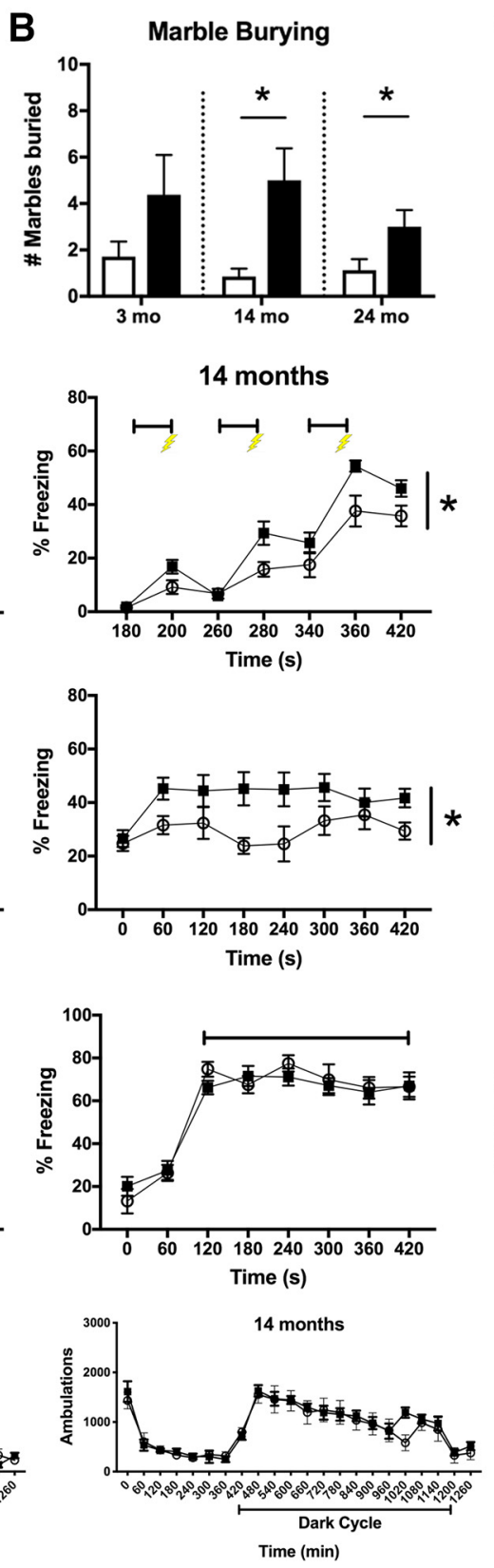

\section{Open Field Test}
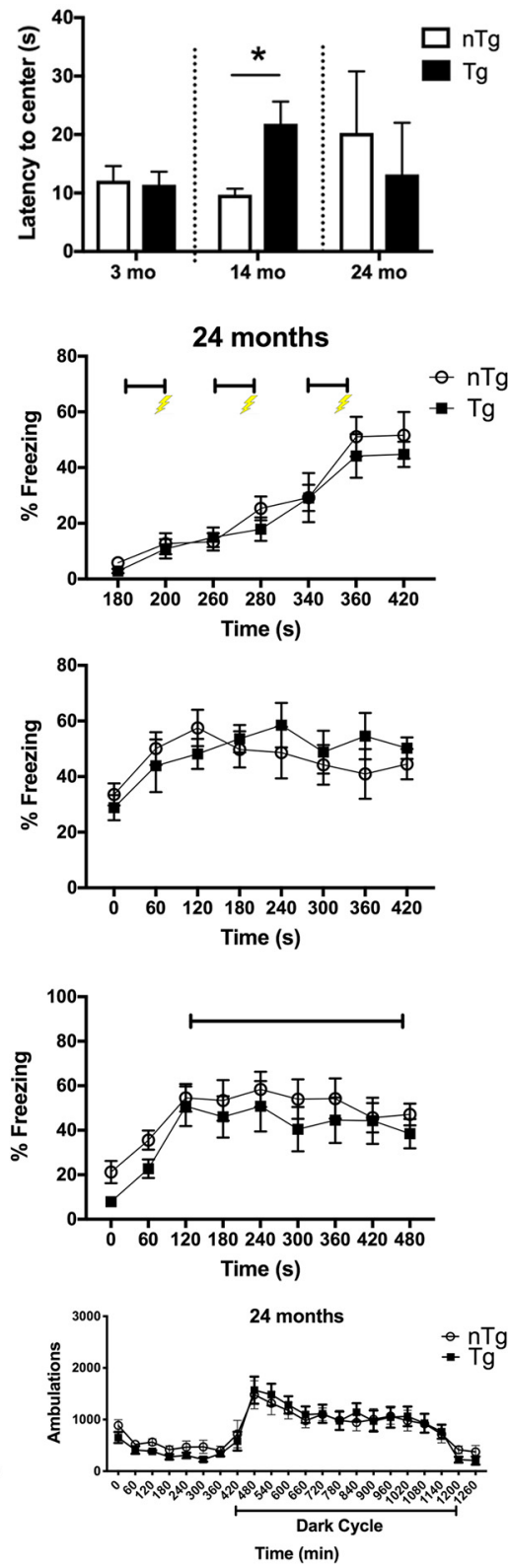
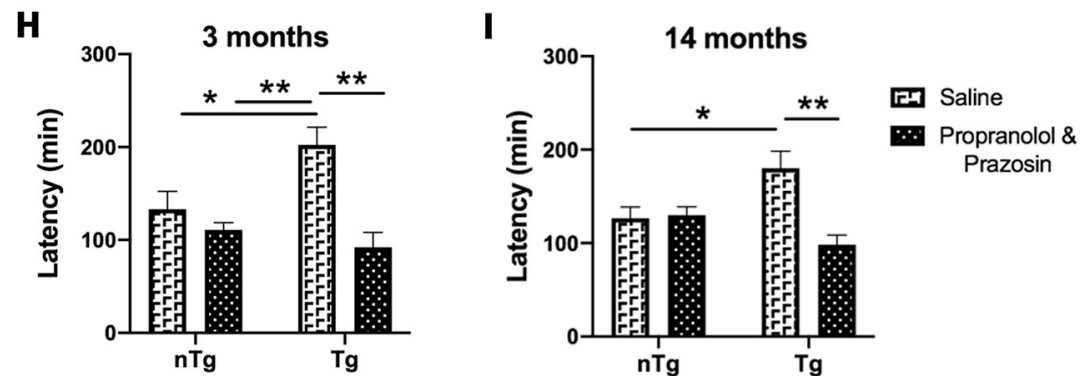

Figure 3. DBH-hSNCA mice display age-dependent behavioral abnormalities similar to the nonmotor symptoms of PD, and adrenergic receptor antagonists normalize sleep latency. $A$, The $3-$ and 14-month-old Tg mice have increased sleep latencies. $\boldsymbol{B}, \boldsymbol{C}$, Tg mice display anxiety-like behavior by marble-burying test at 14 and 24 months $(\boldsymbol{B})$ and latency to re-enter the center in the open field test at 14 months (C). D, E, There is a significant effect of genotype at 14 months, with Tg mice exhibiting a significantly larger percentage of time freezing during fear training (middle; bars represent tone presentation; bolt represents footshock; $\boldsymbol{D}$ ) and contextual learning $(\boldsymbol{E})$. $\boldsymbol{F}$, There was no effect of genotype in the percentage of time freezing during a cued test at any age. $\boldsymbol{G}$, Ambulatory behavior does not differ by genotype at any age. $\boldsymbol{H}, \boldsymbol{I}$, The increased sleep latency observed in 3-month-old $(\boldsymbol{H})$ and 14 -month-old $(\boldsymbol{I}) \mathrm{Tg}$ mice was reduced by a cocktail of propranolol ( $\beta$-adrenergic receptor antagonist) and prazosin ( $\alpha 1$-adrenergic receptor antagonist), while no effect was observed in $\mathrm{nTg}$ mice at either age. $\boldsymbol{A}-\boldsymbol{C}$, Students $t$ test of genotype \pm SEM. $\boldsymbol{D}-\mathbf{G}$, Repeated-measures ANOVA \pm SEM. $\boldsymbol{H}, \boldsymbol{I}$, Two-way ANOVA \pm SEM. ${ }^{*} p<0.05,{ }^{* *} p<0.01,{ }^{* * *} p<0.001$ 

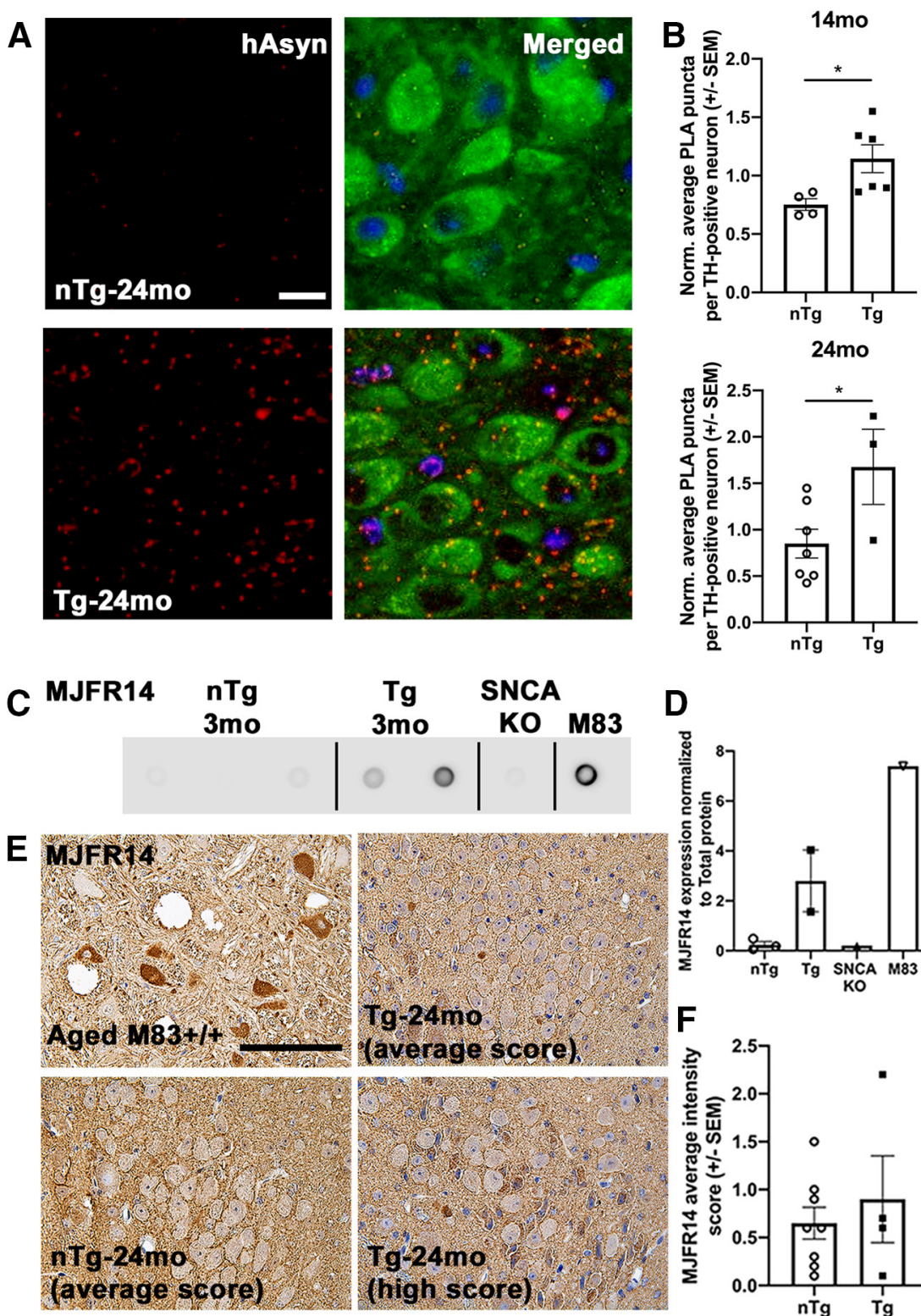

G

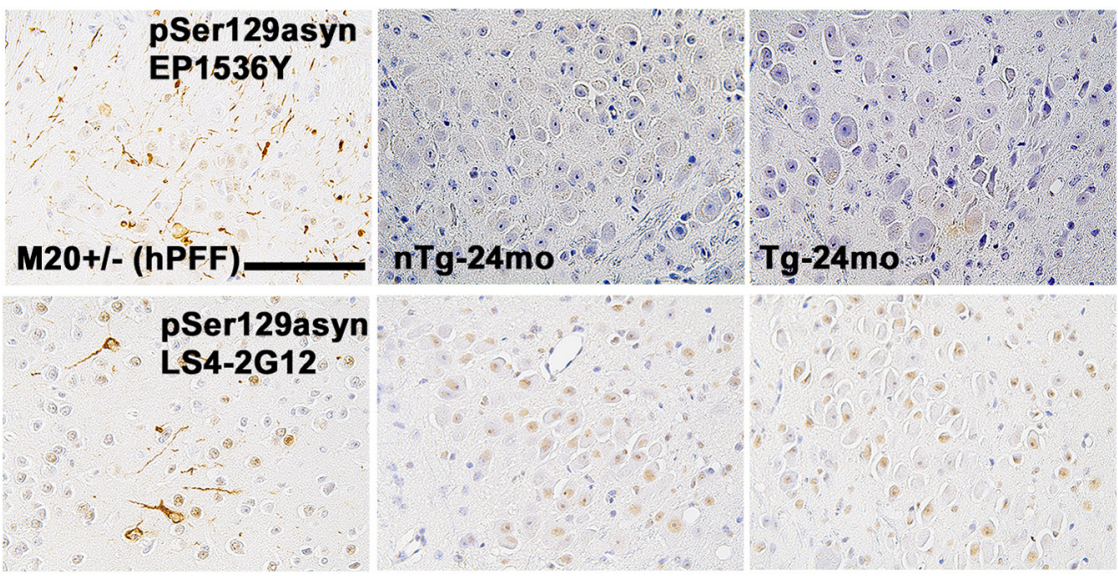

Figure 4. DBH-hSNCA LC neurons contain oligomeric and conformation-specific asyn. $\boldsymbol{A}$, Representative images of oligomerized asyn (hAsyn; red) in LC neurons of (TH; green) 24-month-old Tg mice, as determined by PLA. B, Quantification of PLA puncta demonstrated significantly more oligomerized asyn (red) in LC neurons of Tg mice. $C$, Dot blot analysis of conformationspecific asyn in the LC from 3-month-old nTg and Tg mice and in brain tissue from SNCA knock-out and M83 ${ }^{+/+}$asyn transgenic mice. D, Quantification of MJFR14 expression normalized to total protein from dot blots. $\boldsymbol{E}$, Representative microphotographs of DAB-immunostained LC sections from 24-month-old mice and positive control tissue from an aged M83 ${ }^{+/+}$asyn latency to enter the center score for one 24-month-old nTg animal was omitted after failing to enter the center during the open field test.

Fear conditioning is a measure of hippocampal-dependent (contextual) or hippocampal-independent (cued) associative learning (Phillips and LeDoux, 1992), and mice lacking NE exhibit impaired contextual learning (Murchison et al., 2004). In a standard fearconditioning paradigm, 14-month-old DBH-hSNCA Tg mice exhibited increased freezing behavior during the fear-training session (Fig. 3D, center; interaction: $F_{(6,120)}=2.735, p=0.0159 ; n$ $=8 \mathrm{nTg}, n=14 \mathrm{Tg}$ ), as well as during the contextual test (Fig. 3E, center; effect of genotype: $\left.F_{(1,20)}=5.566, p=0.0286\right)$, with no differences in freezing behavior during the cued test (Fig. 3F; interaction: $\left.F_{(7,160)}=0.5146, p=0.8128\right)$. No genotype differences were found at 3 or 24 months in the fear training (Fig. $3 D$; at 3 months: interaction, $F_{(6,72)}=1.082$, $p=0.3815, n=7$; at 24 months: interaction, $F_{(6,78)}=0.3783, p=0.8908, n=8$ $\mathrm{nTg}$ and $n=7 \mathrm{Tg}$ ), the contextual test (Fig. $3 E$; at 3 months: interaction, $F_{(7,84)}$ $=0.1477, n=7 ; p=0.9938$; at 24 months: interaction, $F_{(7,91)}=1.040, p=0.4089$, $n=8 \mathrm{nTg}$ and $n=7 \mathrm{Tg}$ ), or the cued test (Fig. $3 F$; at 3 months: interaction, $F_{(8,96)}$ $=1.508, p=0.1645, n=7$; at 24 months: interaction, $F_{(8,104)}=0.2766, p=0.9723$, $n=8 \mathrm{nTg}$ and $n=7 \mathrm{Tg}$ ).

Because disruption in locomotor activity can affect behavioral testing, we evaluated the locomotion over $24 \mathrm{~h}$ and found no genotype differences at 3 months (interaction: $F_{(21,252)}=1.033$, $p=0.4233, n=7$ ), at 14 months (interaction: $F_{(21,231)}=0.6319, p=0.8929, n=7$ $\mathrm{nTg}$ and $n=6 \mathrm{Tg}$ ), or at 24 months $\left(F_{(21,273)}=0.06975, p=0.8349, n=8\right.$ $\mathrm{nTg}$ and $n=7 \mathrm{Tg}$ ) of age (Fig. $3 F$ ). Initially, all groups had high levels of activity, as would be expected in a novel environment, which decreased as mice habituated to the test apparatus. Ambulations increased normally in all genotypes at commencement of the dark phase, when mice are typically

transgenic mouse with conformation-specific asyn (MJFR14). $\boldsymbol{F}$, Semiquantification analysis of MJFR14 intensity. G, Representative DAB-immunostained LC sections from 24-month-old mice and hippocampal-positive control tissue from 6-month-old ${\mathrm{M} 2 \mathrm{O}^{+/}-}_{\text {asyn }}$ transgenic mice after brain inoculation with human asyn preformed fibrils (hPFF) to seed asyn inclusions with antibodies against pSer129 asyn (EP1536Y and LS42G12). Scale bars: hAsyn, $15 \mu \mathrm{m} ; \mathrm{pSer} 129$ and MJFR14, $100 \mu \mathrm{m}$. Student's $t$ test \pm SEM, ${ }^{*} p<0.05$. 


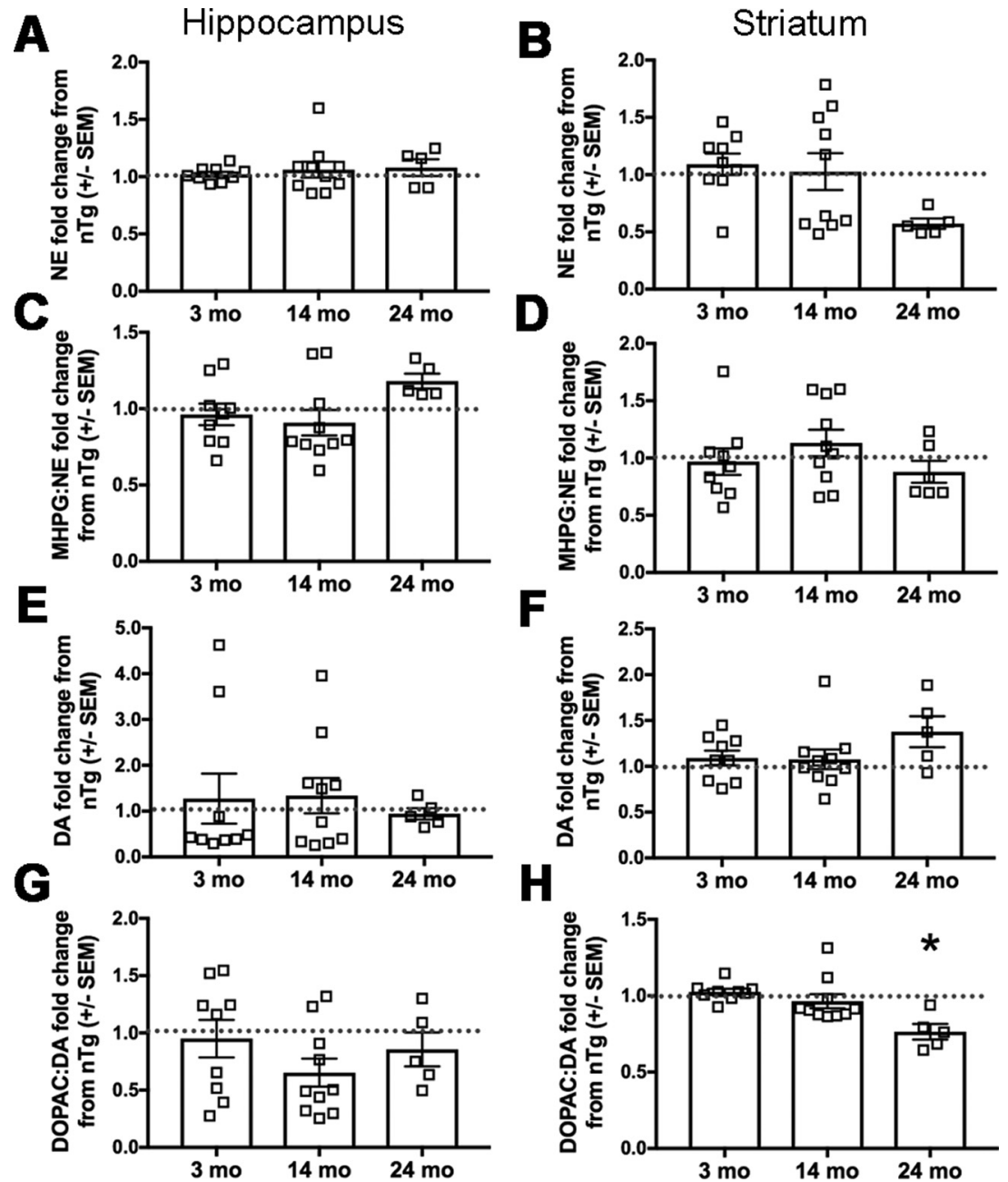

Figure 5. Human asyn expression in $L C$ neurons impacts striatal dopamine metabolism in aged DBH-hSNCA mice. Catecholamine and catecholamine metabolite tissue content from hippocampus and striatum was measured by HPLC. $A$, Hippocampal NE is not affected by genotype. $\boldsymbol{B}$, Striatal NE is reduced at 24 months but does not reach statistical significance. $\boldsymbol{C}, \boldsymbol{D}$, The NE metabolite MHPG/NE ratio does not differ at any age in the hippocampus $(\boldsymbol{C})$ or striatum $(\boldsymbol{D}) . \boldsymbol{E}, \boldsymbol{F}$, Dopamine content is not affected at any age in hippocampus $(\boldsymbol{E})$ or striatum $(\boldsymbol{F}) . \boldsymbol{G}, \boldsymbol{H}$, The ratio of the DA metabolite DOPAC to DA is unaffected in the hippocampus $(\boldsymbol{G})$ but is significantly reduced in the striatum $(\boldsymbol{H})$ of Tg mice at 24 months. Student's $\boldsymbol{t}$ test of genotype for each age group \pm SEM, ${ }^{*} p<0.05$.

more active, and decreased once the next light cycle began. The behavioral results above (i.e., increased arousal and anxiety-like behavior) were consistent with overactive LC-NE transmission. To test this hypothesis, an additional cohort of 3- and 14-monthold $D B H$-hSNCA mice underwent sleep latency testing following the administration of saline or a cocktail of propranolol ( $\beta$-adrenergic receptor antagonist) and prazosin $(\alpha 1$-adrenergic receptor antagonist). We chose the sleep latency paradigm for these experiments because (1) LC activity is most tightly coupled to arousal state, (2) increased sleep latency was the most robust phenotype we observed, and (3) increased sleep latency was evident at the earliest time point ( 3 months). Similar to baseline testing, 3- and 14-month-old Tg mice that were administered saline took longer to fall asleep than nTg littermates. However, adrenergic receptor blockade normalized sleep latency in 3- or 14-month-old Tg mice, while propranolol and prazosin administration had no effect on sleep latency in nTg mice [3-month-old mice: (Fig. $3 H$ ) interaction, $F_{(1,16)}=7.367, p=0.0153, n=5$; 14month-old mice: (Fig. $3 I$ ) interaction, $F_{(1,18)}=1.27, p=0.0035$, $n=6 \mathrm{nTg}$ and $n=5 \mathrm{Tg}]$.
Human asyn forms oligomers and conformation-specific asyn in LC neurons at 14 and 24 months of age To determine whether transgenic expression of human asyn in LC neurons resulted in the formation of asyn oligomers, tissue sections containing the LC were analyzed using a human asyn PLA. Tg LC neurons displayed more asyn puncta per TH-positive neuron than $\mathrm{nTg}$ LC neurons at 14 months of age (Fig. $4 A, B ; t_{(8)}=2.53, p=0.0352$; $n=4 \mathrm{nTg}$ and $n=6 \mathrm{Tg})$ and at 24 months of age (Fig. $4 A, B ; t_{(8)}=2.402$, $p=0.0430 ; n=12 \mathrm{nTg}$ and $n=3 \mathrm{Tg}$ ). To investigate whether the oligomeric asyn had altered conformation, we probed LC tissue lysates from 3-month-old $\mathrm{Tg}$ and $\mathrm{nTg}$ mice for immunoreactivity against an asyn filament conformationspecific antibody (MJFR14) on immunedot blots, using Snca knock-out and $\mathrm{M} 3^{+/+}$asyn transgenic mouse tissues as negative and positive controls, respectively. We found that $\mathrm{Tg}$ mice displayed robust MJFR14-IR (Fig. 4C,D) compared with nTg and Snca knock-out control. We next probed for conformation-specific asyn properties using an immunohistological approach and found significant variability in the intensity of MJFR14-IR in LC neuron sections of 24-month-old $\mathrm{Tg}$ and $\mathrm{nTg}$ mice that did not reach statistical significance between genotypes (Fig. 4E,F). Last, because conformation-specific and aggregated asyn have been associated with increased pSer129, and because labeling these forms of the protein is commonly used to identify asyn inclusions (Fujiwara et al., 2002; Wakamatsu et al., 2007; Schell et al., 2009), we immunolabeled LC tissue sections with antibodies specific for fibril-rich asyn (Syn-F1; data not shown) and asyn pSer129 (EP1536Y and LS4-2G12; Fig. 4G) and found no differences between genotypes, suggesting that at 24 months of age there are oligomeric aggregates, but no mature higher-order asyn inclusions in DBH-hSNCA mice.

\section{Human asyn expression in LC neurons impacts striatal} dopamine metabolism in 24-month-old mice

Dysregulated catecholamine metabolism and degeneration of catecholaminergic neurons are well established features of PD (Iversen et al., 1983; Mann et al., 1983; Hirsch et al., 1988; Fearnley and Lees, 1991). Therefore, we measured catecholamine levels using HPLC. Hippocampal and striatal tissue content of $\mathrm{NE}$, the NE metabolite MHPG, DA, and the DA metabolite DOPAC were quantified, revealing that NE (Fig. $5 A, B$ ) and DA (Fig. $5 E, F$ ) were not significantly affected in the hippocampus or striatum at any age. Similarly, the ratio of the major NE metabolite MHPG to NE was unaffected (Fig. 5C,D). The ratio of the DA metabolite DOPAC to DA in the hippocampus was 
A
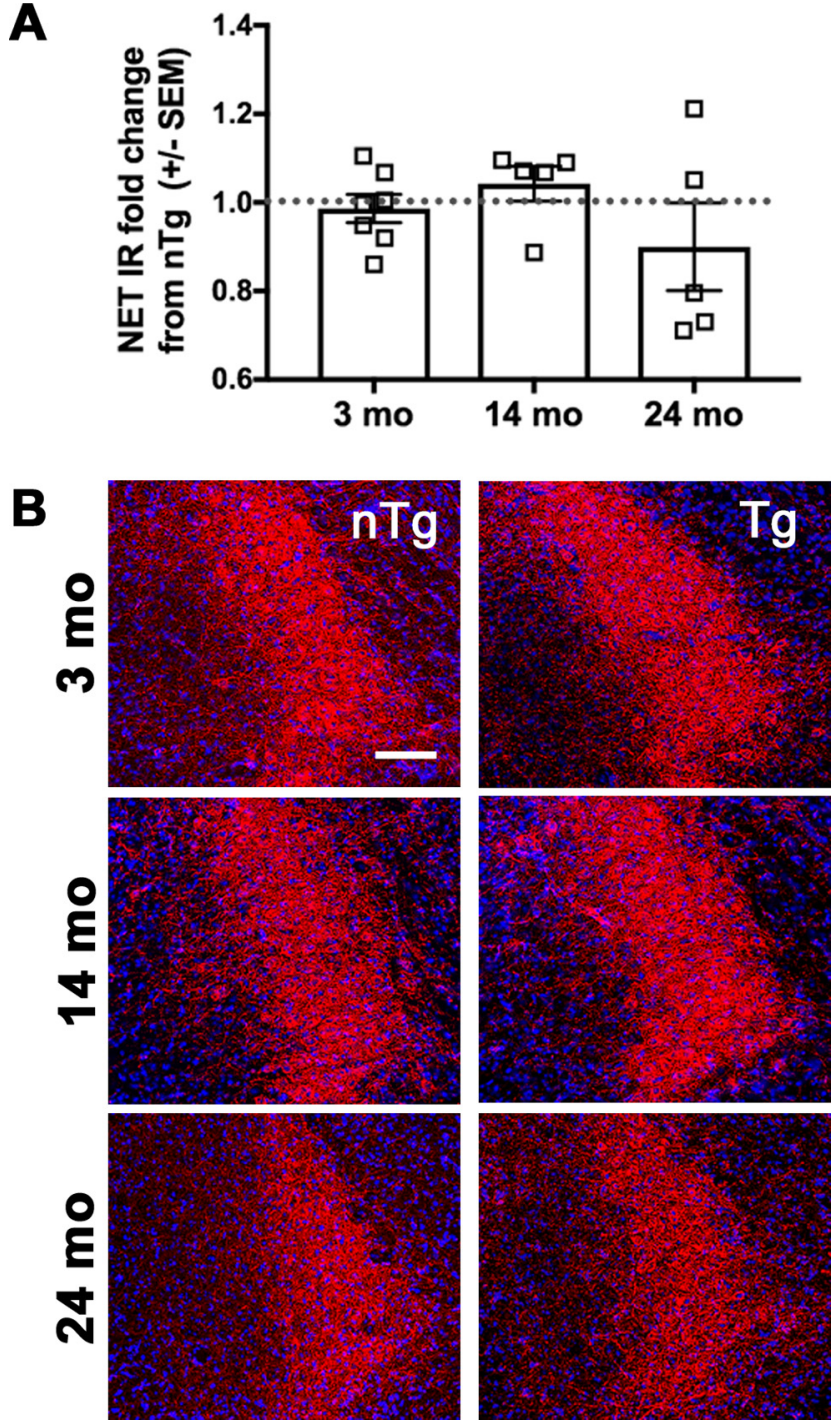

Figure 6. Human asyn expression does not affect LC integrity. The percentage of IR for NET-expressing LC cell bodies (red) does not differ by genotype at 3, 14, or 24 months. $\boldsymbol{A}, \boldsymbol{B}$, Student's $t$ test of the mean IR by genotype for each age group, graphed as the fold change $\mathrm{Tg}$ from $\mathrm{nTg}$ mean $\pm \operatorname{SEM}(\boldsymbol{A})$; representative images $(\boldsymbol{B})$. Scale bar, $50 \mu \mathrm{m}$

unaltered (Fig. $5 G$ ), but was significantly reduced in the Tg striatum at 24 months (Fig. $5 H ; t_{(10)}=3.546, p=0.0046 ; n=9 \mathrm{nTg}$ and $n=6 \mathrm{Tg}$ ), which is consistent with decreased DA turnover.

\section{Human asyn expression does not affect LC neuronal integrity}

LC neurons were visualized using NET-IR. NET is a reliable marker of LC neurons, and its expression is reduced in $\mathrm{PD}$ patients (Remy et al., 2005). Using a standard ROI, no difference in the percentage of NET-IR was detected between genotypes at 3 months (Fig. $6 ; t_{(17)}=0.4537, p=0.6558 ; n=9 \mathrm{nTg}$ and $n=10$ Tg), 14 months $\left(t_{(10)}=0.8908, p=0.3939 ; n=7 \mathrm{nTg}\right.$ and $n=5$ $\mathrm{Tg})$, or 24 months $\left(t_{(8)}=0.8069, p=0.4430 ; n=5\right)$.

\section{Elevation of tyrosine hydroxylase in the LC of $\mathrm{DBH}-\mathrm{hSNCA}$} mice

$\mathrm{TH}$ is the rate-limiting enzyme in NE and DA synthesis, and its long-term activity depends on its expression levels (Levitt et al., 1965; Haycock, 1993; Kumer and Vrana, 1996). To determine whether TH expression in the LC is affected by human asyn, we assessed TH-IR in sections from 3-, 14-, and 24-month-old mice. TH-IR was normalized to NET-IR to control for potential differences in bregma level between sections. $\mathrm{TH}$ expression was increased in Tg LC neurons (Fig. $7 A, B$ ) at both 3 months of age $\left(t_{(17)}=2.154, p=0.0459 ; n=9 \mathrm{nTg}\right.$ and $\left.n=10 \mathrm{Tg}\right)$ and 14 months of age $\left(t_{(10)}=2.463, p=0.0335 ; n=7 \mathrm{nTg}\right.$ and $\left.n=5 \mathrm{Tg}\right)$. Western blot analysis from 3-month-old TH-EGFP-expressing LC neurons (Fig. 7C,D) confirmed higher $\mathrm{TH}$ expression in $\mathrm{Tg}$ animals $\left(t_{(10)}=3.837, p=0.0033 ; n=6 \mathrm{nTg}\right.$ and $\left.n=5 \mathrm{Tg}\right)$.

\section{Human asyn expression in LC neurons affects expression of} local inflammatory markers

A wealth of studies suggests that dysregulated noradrenergic neurotransmission is associated with inflammation (Butkovich et al., 2018), and that dysregulation of the LC-NE system could contribute to the chronic neuroinflammation observed in PD (Fujita et al., 1998; Gyoneva and Traynelis, 2013; Johnson et al., 2013). To determine astrocyte activation, we quantified glial fibrillary acidic protein (GFAP) IR, commonly used as a protein marker of astrogliosis (Eng and Ghirnikar, 1994), in the LC. There was a significant increase in astrocytic GFAP expression in the LC of Tg animals at 24 months (Fig. 8A,B; $t_{(10)}=2.744, p=0.0207 ; n=7 \mathrm{nTg}$ and $n=4 \mathrm{Tg}$ ), with no difference found at 3 and 14 months between $\mathrm{Tg}$ and $\mathrm{nTg}$ animals. To determine whether human asyn expression in LC neurons affects the number of myeloid cells in the brain (both brain-resident microglia and potentially infiltrating monocytes), we quantified the number of ionized calcium-binding adaptor molecule 1 (Iba1)-postive cells in the LC by immunofluorescence. At 14 months, there was a significant decrease in the number of Iba1-expressing cells in the LC of $\mathrm{Tg}$ animals (Fig. $8 C, D ; t_{(13)}=2.845, p=0.0138 ; n=7$ ), with no changes at other ages.

Human asyn expression in LC neurons is associated with loss of hippocampal LC fibers at $\mathbf{2 4}$ months

The LC is the sole source of hippocampal NE, which is necessary for proper memory formation and retrieval (Devauges and Sara, 1991). Noradrenergic LC fibers express NET, and PD brain tissue shows substantial LC denervation (Pavese et al., 2011). To determine whether hippocampal LC projections degenerate in DBH-hSNCA mice, we examined NET-IR in the CA1, CA3, and dentate gyrus regions of the hippocampus. At 24 months, we found a reduction in LC fibers in the dentate gyrus (Fig. 9C,D; $t_{(10)}=2.974, p=0.0156 ; n=6 \mathrm{nTg}$ and $n=5 \mathrm{Tg}$ ), with a trend for reduction in CA1 (Fig. $9 A, B ; t_{(10)}=1.899, p=0.0901, n=6 \mathrm{nTg}$ and $n=5 \mathrm{Tg}$ ) and CA3 (Fig. $9 E, F ; t_{(10)}=1.538, p=0.1585, n=6$ $\mathrm{nTg}$ and $n=5 \mathrm{Tg}$ ). No differences were observed in mice at 3 or 14 months.

\section{Hippocampal astrogliosis and changes in number of} hippocampal Iba1-expressing cells in $D B H$ - $h S N C A$ mice To determine whether degeneration of hippocampal LC projections is associated with inflammation, GFAP-IR was visualized in the CA1, CA3, and dentate gyrus regions of the hippocampus. At 14 months, there was a significant increase in GFAP expression in CA1 (Fig. $10 A, B ; t_{(19)}=2.723, p=0.0135, n=12 \mathrm{nTg}$ and $n=9 \mathrm{Tg}$ ) and CA3 (Fig. 10E,F; $t_{(19)}=2.275, p=0.0347, n=12$ $\mathrm{nTg}$ and $n=9 \mathrm{Tg}$ ), but not the dentate gyrus (Fig. 10C, $D ; t_{(19)}=$ 1.607, $p=0.1246, n=12 \mathrm{nTg}$ and $n=12 \mathrm{Tg}$ ) of Tg mice compared with $\mathrm{nTg}$. Similar to what we observed in the LC, the 


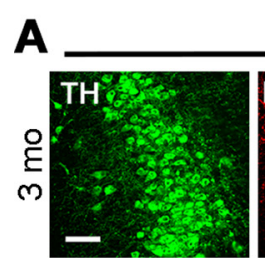

$\mathrm{nTg}$
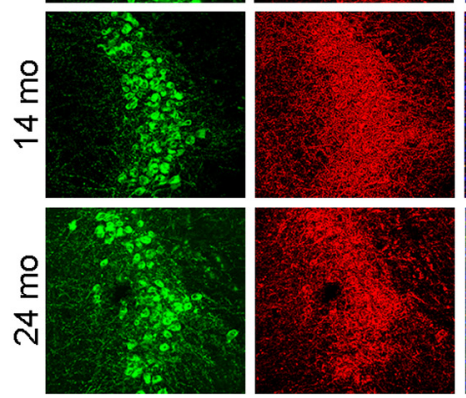

\section{B}

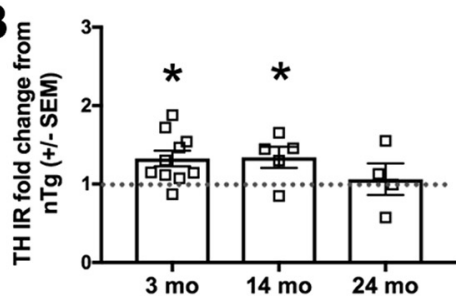

$\mathrm{Tg}$
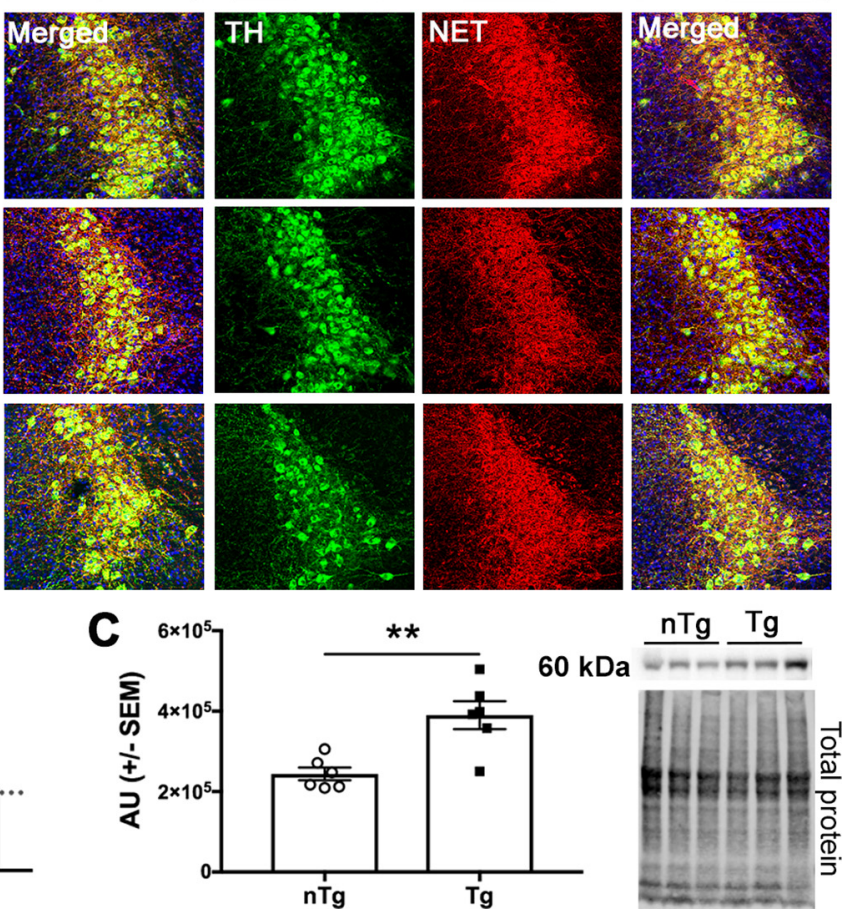

Figure 7. Tyrosine hydroxylase levels are elevated in young DBH-hSNCA Tg mice. TH (green) immunoreactivity is increased in LC neurons (NET; red) at 3 and 14 months of age. $\boldsymbol{A}$, Representative immunofluorescent images. $\boldsymbol{B}$, TH IR mean normalized to NET IR mean and expressed as the fold change of Tg from nTg mean \pm SEM percentage of IR. $\boldsymbol{C}$, Western blot analysis of LC neurons from 3-month-old DBH-hSNCA $\times$ TH-EGFP mice confirms increased TH abundance. Data graphed as arbitrary densitometric units (AU) were normalized to total protein \pm SEM. Representative Western blot images of TH (top) and total protein stain (bottom). Student's $t$ test of $n T g$ and $\operatorname{Tg}$ at each age, $n=5-10$. Scale bar, $50 \mu m$. ${ }^{*} p<0.05$, ${ }^{* *} p<0.01$.
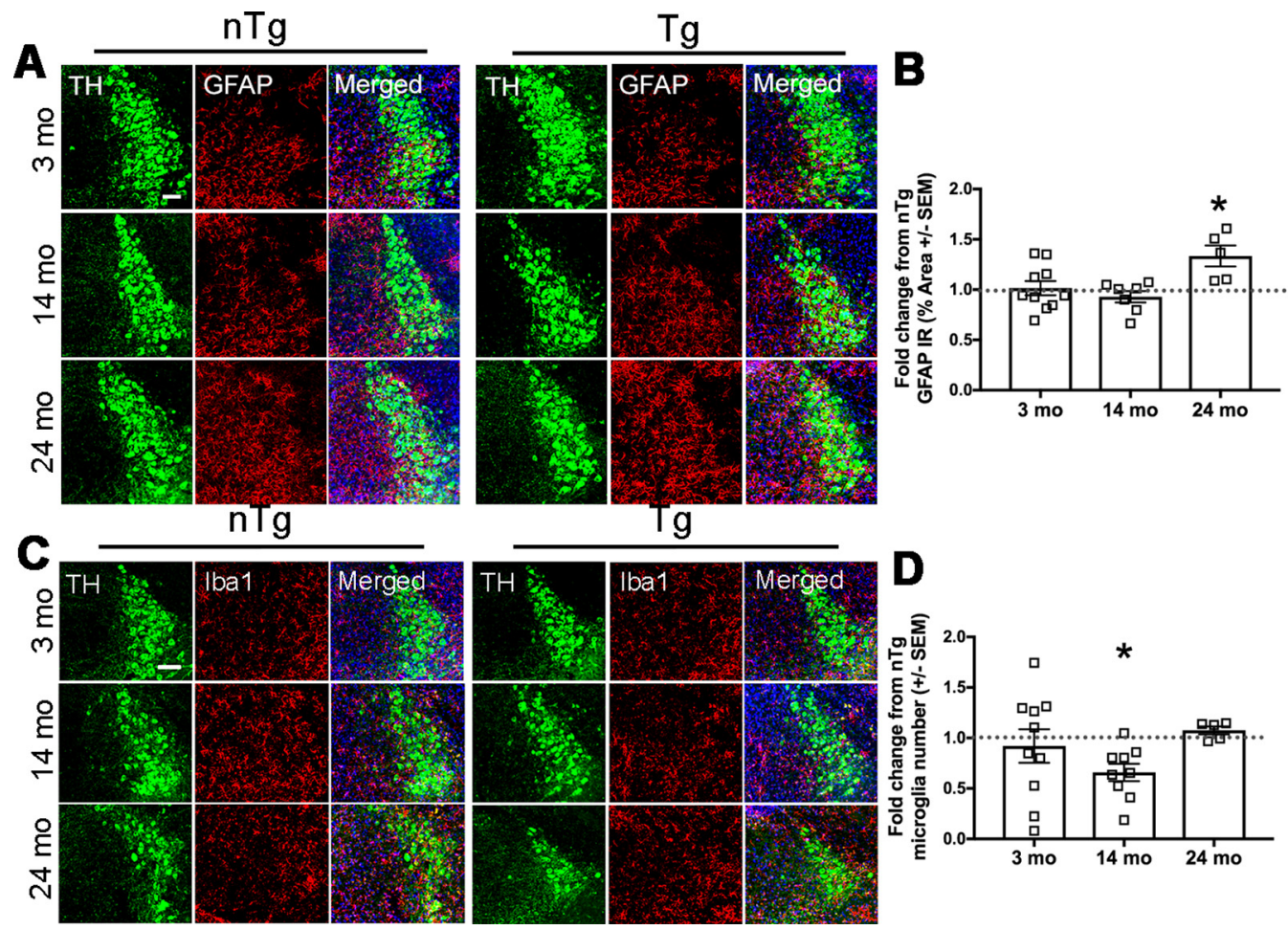

Figure 8. Human asyn in LC neurons affects the expression of local inflammatory markers. The expression of astrocytic GFAP (red) is increased in the Tg LC (TH; green) at 24 months of age. $\boldsymbol{A}$, Representative immunofluorescent images. $\boldsymbol{B}$, Quantification of the GFAP percentage of IR in the LC as the percentage of ROI graphed as the fold change in Tg IR from $n T g$ mean IR \pm SEM. There are fewer lba1-positive cells (red) in the LC (TH; green) at 14 months. C, Representative immunofluorescent images. D, Microglial count in the LC graphed as the fold change in Tg from $n T g$ lba1-positive cell count \pm SEM. Student's $t$ test of $n T g$ and $\mathrm{Tg}$ for each age group. Student's $t$ test of $\mathrm{nTg}$ and $\mathrm{Tg}$ for each age group. Scale bar, $50 \mu \mathrm{m}$. * $p<0.05$. 

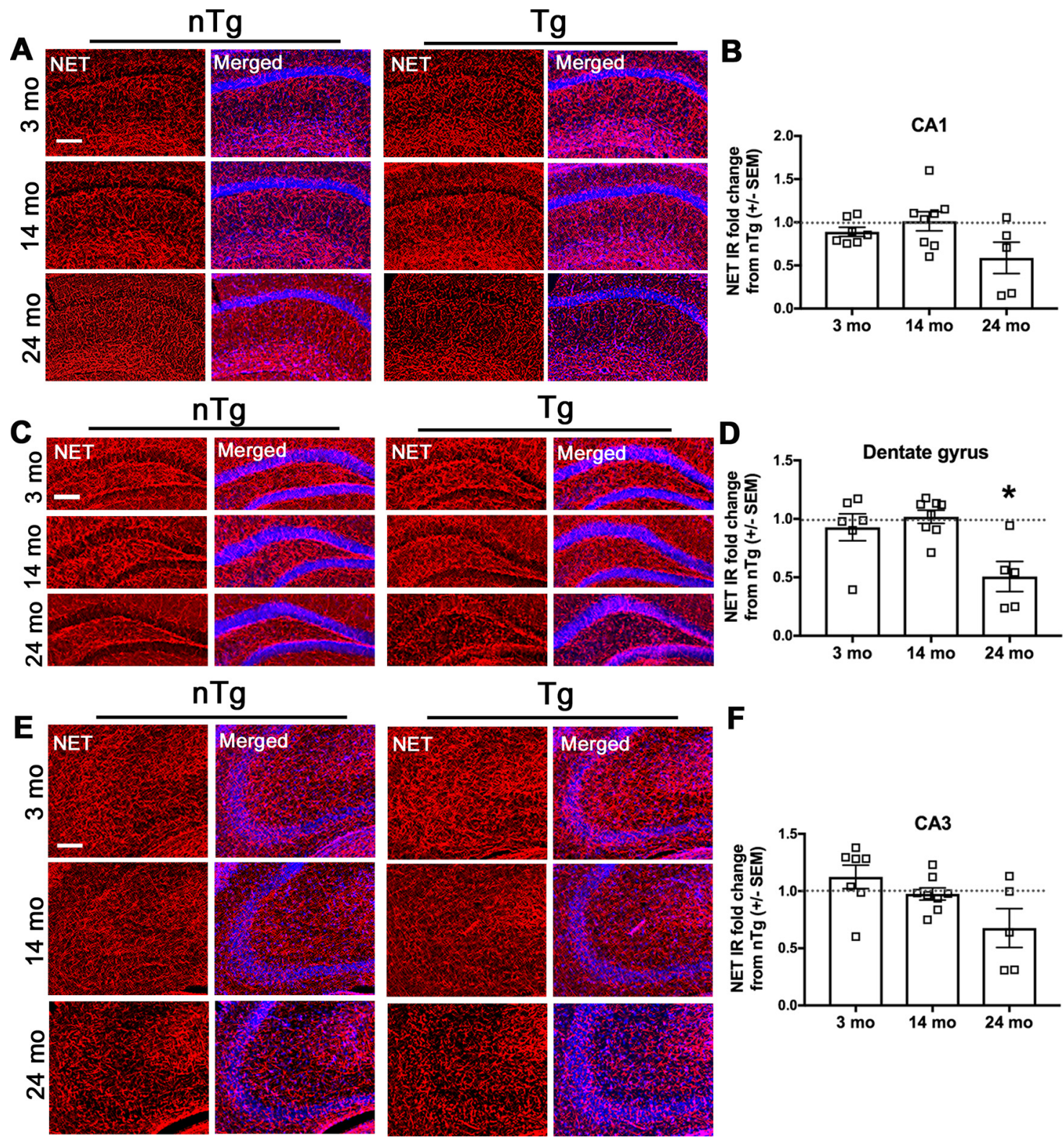

Figure 9. Asyn expression in LC neurons results in age-dependent degeneration of hippocampal LC fibers. NET (red) IR is reduced in the dentate gyrus of Tg mice at 24 months. $A, C, E$, Representative immunofluorescent images of CA1 $(\boldsymbol{A})$, dentate gyrus $(\boldsymbol{C})$, and CA3 $(\boldsymbol{E})$ regions. $\boldsymbol{B}, \boldsymbol{D}, \boldsymbol{F}$, Quantification of NET IR as the percent of area of the R01 in CA1 (B), dentate gyrus $(\boldsymbol{D})$, and CA3 $(\boldsymbol{F})$. Nuclear stain in shown in blue. Student's $t$ test of $\mathrm{nTg}$ and $\mathrm{Tg}$ for each age group, graphed as the mean \pm SEM fold change of $\mathrm{Tg}$ from nTg. Scale bar, $150 \mu \mathrm{m}$. ${ }^{*} p<0.05$.

number of Iba1-expressing cells in CA1 was reduced in Tg mice at 14 months (Fig. 10G,H; $t_{(16)}=2.592, p=0.0196, n=9$ ).

\section{Discussion}

Based on a wealth of evidence (Mavridis et al., 1991; Srinivasan and Schmidt, 2003; Tong et al., 2006; Rommelfanger et al., 2007; Yao et al., 2015), we posit that asyn pathology and degeneration of LC neurons may represent a tipping point in PD progression; therefore, understanding how asyn accumulation in LC neurons affects their function and survival may help to inform the development of new therapeutic agents for earlier interventions. To this end, we developed a new BAC transgenic mouse expressing human wild-type asyn under the control of the noradrenergicspecific $D B H$.

Human asyn was detectable by immunofluorescence in the $\mathrm{Tg}$ LC and in neurons of some (e.g., A4, A5) but not other (e.g.,
A1, A2) additional DBH-expressing brainstem nuclei by immunofluorescence at 3 months. Analysis of total asyn (mouse plus human) by Western blot revealed that the total asyn burden is increased in Tg LC neurons at 3 months. While pSer129-positive and fibrillar pathologic inclusions were not detected in LC neurons at 24 months, increasing the burden of asyn expression in LC neurons resulted in the formation of putative asyn oligomers, as detected by PLA. We did find nonuniform biochemical and immunohistological evidence of conformation-specific asyn-IR (MJFR14) in 3- and 24-month-old Tg mice, suggesting a change in the structural conformation of asyn in some animals, possibly as a consequence of human asyn burden, the corruption of endogenous asyn or another critical intrinsic animal-specific factor such as altered TH. Although we observed no loss of LC cell bodies, NET-expressing fibers were reduced in the hippocampus of 24-month-old mice. This finding resembles the pattern of neuron death observed in $\mathrm{PD}$, with axon terminals degenerating 

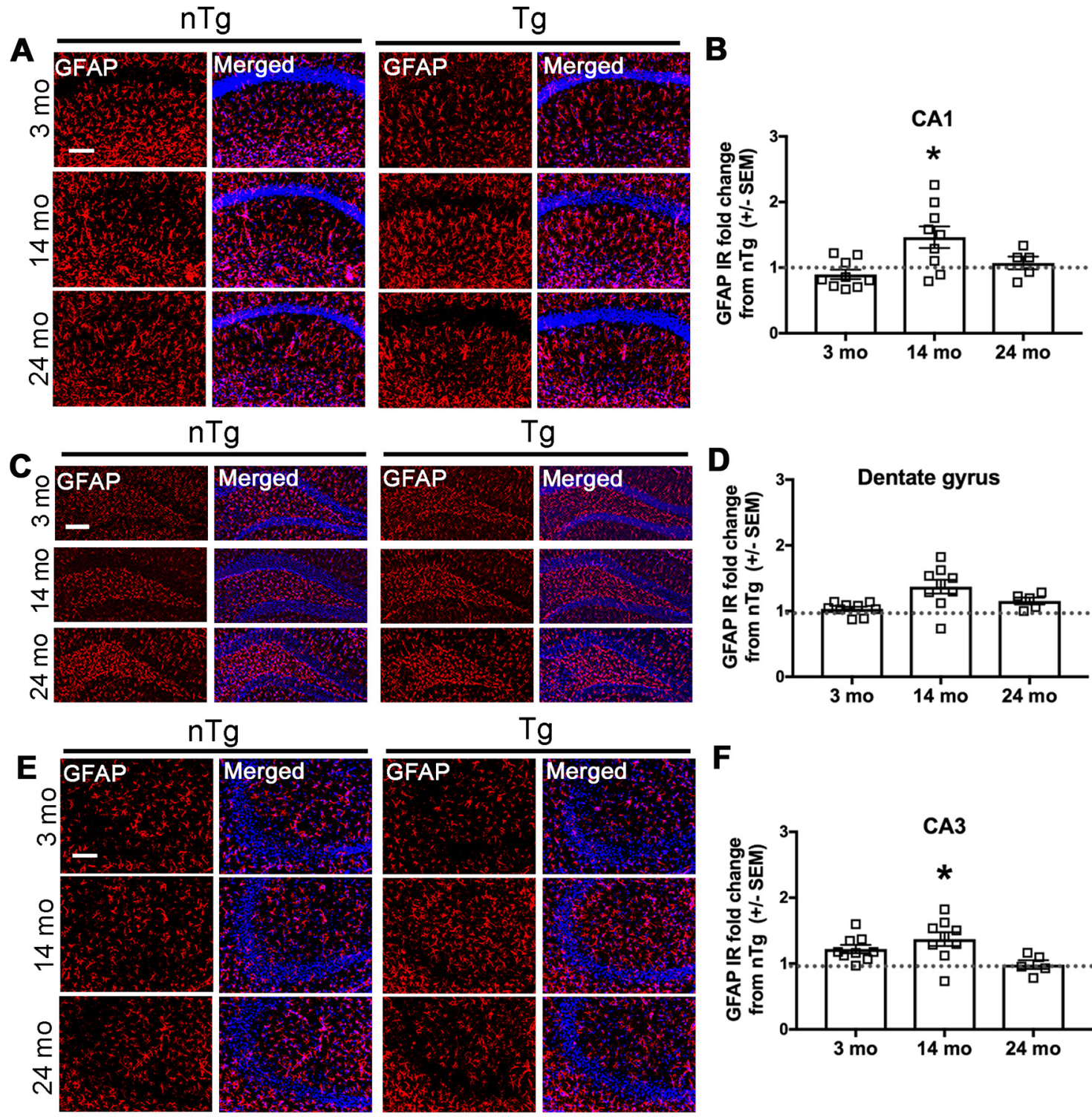

$\operatorname{Tg}$
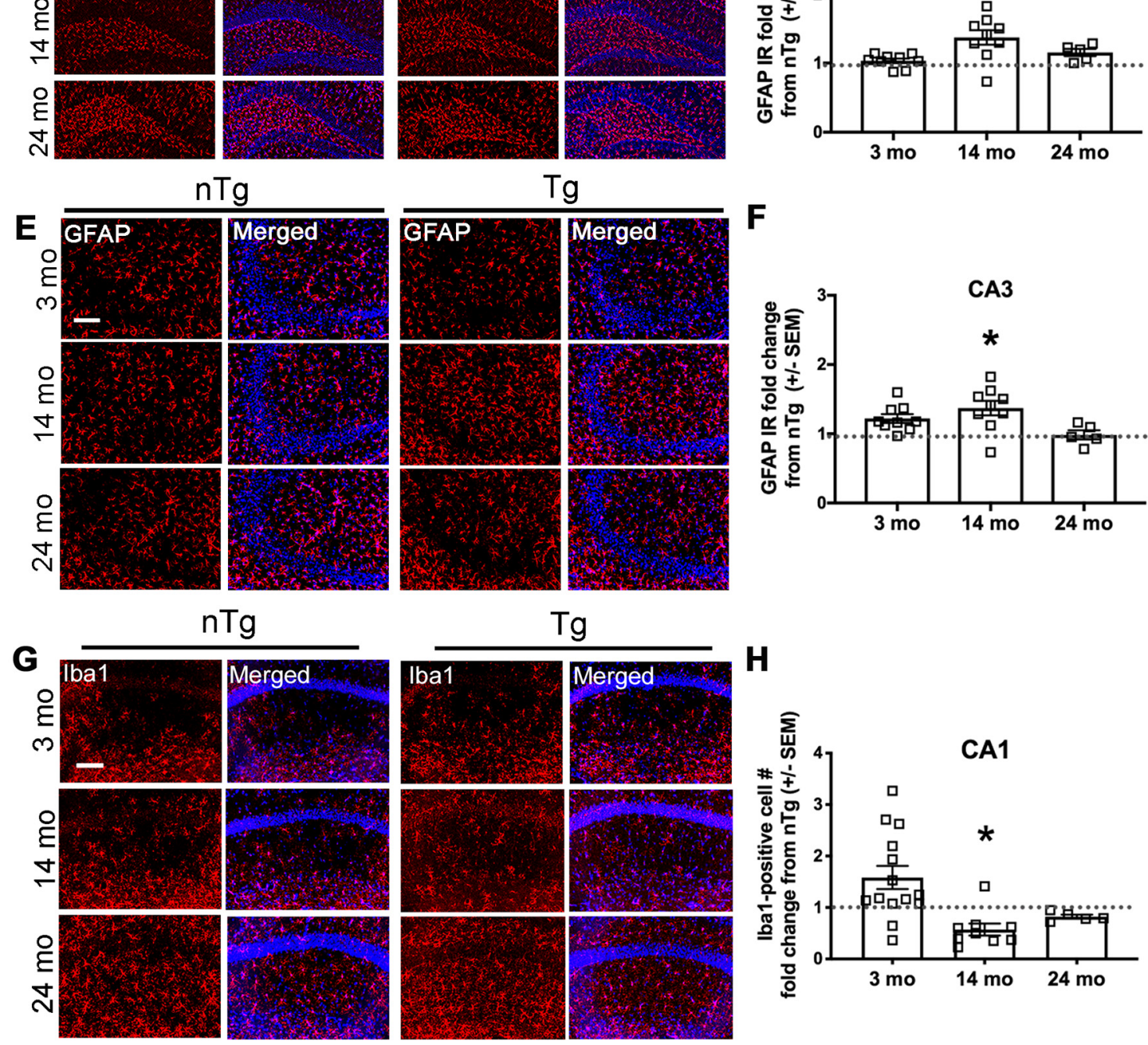

Figure 10. Hippocampal astrocytic GFAP expression is increased, with fewer Iba1-expressing cells in CA1, in 14-month-old Tg DBH-hSNCA mice. At 14 months, Tg mice have significantly more GFAP (red) expression than $\mathrm{nTg}$ mice in the CA1 region of the hippocampus. $\boldsymbol{A}, \boldsymbol{C}, \boldsymbol{E}$, Representative immunofluorescent images of $C A 1(\boldsymbol{A})$, dentate gyrus $(\boldsymbol{C})$, and $C A 3(\boldsymbol{E})$ regions. $\boldsymbol{B}, \boldsymbol{D}$, $\boldsymbol{F}$, Quantification of GFAP IR as the percentage area of the ROI in CA1 (B), dentate gyrus (D), and CA3 (F). At 14 months, Tg mice have fewer lba1-expressing cells in hippocampal region CA1. $\boldsymbol{G}$, Representative immunofluorescent images of Iba1-expressing cells (red). $\boldsymbol{H}$, Quantification of Iba1-expressing cells in CA1 graphed as Tg fold change from $\mathrm{nTg}$ mean \pm SEM. Nuclear stain in blue. Student's $t$ test of $\mathrm{nTg}$ and $\mathrm{Tg}$ for each age group, graphed as the mean \pm SEM fold change in Tg from nTg. Scale bar, $150 \mu \mathrm{m}$. ${ }^{*} p<0.05$. 
before frank cell loss in the LC (Hornykiewicz, 1998). Interestingly, the selective loss of LC fibers in the dentate gyrus of $D B H$ - $h S N C A$ mice is reminiscent of what we observed in a TgF344-AD rat model of Alzheimer's disease that accumulates tau pathology in the LC (Rorabaugh et al., 2017). To determine the functional outcome of human asyn expression in LC neurons, we measured catecholamine levels in the hippocampus and striatum. Despite the loss of hippocampal LC fibers at 24 months, we did not detect changes in hippocampal $\mathrm{NE}$ content by HPLC, which may indicate a compensatory enhancement in NE synthesis. We observed a trend toward decreased striatal NE at 24 months, but it was not statistically significant. With the sparse noradrenergic innervation to the striatum, it is possible that changes in NE neurotransmission are detectable there before more densely innervated regions. Dysregulated DA metabolism is a central feature of PD (Leenders et al., 1990), and midbrain dopaminergic innervation to the striatum is modulated by LC-NE (Lategan et al., 1990; Grenhoff et al., 1993; Rommelfanger et al., 2007; Rommelfanger and Weinshenker, 2007). Studies of catecholamine function in rodents show that enhancing LC-NE stimulates midbrain DA release in the striatum, whereas LC lesions or NE deficiency reduce striatal DA release (Lategan et al., 1990; Grenhoff et al., 1993; Schank et al., 2006). We found that at 24 months, Tg mice had a reduced striatal ratio of DOPAC/DA and a trend toward increased DA, suggesting that human asyn expression in aging $\mathrm{LC}$ neurons causes a reduction in striatal DA turnover. Future studies will determine whether NE innervation to midbrain DA neurons is reduced in 24month-old $D B H$-hSNCA mice and whether the loss of noradrenergic transmission impairs striatal DA release. While no significant differences were detected in hippocampal or striatal NE content at any age, Tg LC neurons had increased TH expression at 3 and 14 months relative to $\mathrm{nTg}$ littermates, suggesting an increased capacity for NE synthesis.

Neuroinflammation is a central feature of PD pathology (McGeer et al., 1988; Gerhard et al., 2006; Tansey and Goldberg, 2010), with extensive evidence of changes in microglial activation in brain regions that degenerate in PD (Kim and Joh, 2006; Tansey and Goldberg, 2010), and we know that microglia and astrocyte functions are modulated by NE neurotransmission (Fahrig, 1993; Heneka et al., 2010; Bharani et al., 2017). Unexpectedly, we observed fewer Iba1-expressing cells in the LC and CA1 regions of the hippocampus of DBH-hSNCA mice at 14 months compared with nTg littermates. It has been reported that $\mathrm{NE}$ can modulate microglial activity, and the functional outcome of microglia adrenergic receptor activation appears to depend on the physiological context (Fujita et al., 1998; Gyoneva and Traynelis, 2013; Johnson et al., 2013). At 14 months, there was an increase in hippocampal astrocytic GFAP expression. Astrocytes throughout the brain are activated by NE, and adrenergic receptor signaling stimulates calcium transients and promotes the release of inflammatory signaling molecules by astrocytes (Norris and Benveniste, 1993; Duffy and MacVicar,
1995; Paukert et al., 2014). Although there is no direct evidence by HPLC that increased hippocampal GFAP expression at 14 months is because of changes in noradrenergic neurotransmission, it is still possible that there is NE involvement as adrenergic receptor antagonists normalized sleep latency at this age. Further studies are required to determine whether increased GFAP activity is because of dysregulated NE neurotransmission or a response related to changes in neuronal homeostasis related to oligomeric asyn in the terminals as increased GFAP-IR in the hippocampus can occur before loss of LC projections (Eng and Ghirnikar, 1994; Bharani et al., 2017).

Historically, the LC has been implicated in arousal state and stress responses. For example, LC activity tracks with sleep cycles (with highest firing during wake and immediately preceding sleep-wake transitions), and chemogenetic or optogenetic activation of LC neurons increases wakefulness (Carter et al., 2010; Vazey and Aston-Jones, 2014; Porter-Stransky et al., 2019). Furthermore, the LC is activated by stress, and stimulation of LC neurons elicits anxiety-like behaviors (Valentino and Van Bockstaele, 2008; McCall et al., 2015). DBH-hSNCA mice exhibited age-dependent behavioral phenotypes that peaked at 14 months and are consistent with LC hyperactivity and increased NE transmission. Specifically, compared with nTg littermates, $D B H$-hSNCA mice displayed increased arousal (as measured by latency to fall asleep), anxiety-like behavior (as measured by marble burying and latency to re-enter the center of an open field), and stress responses (as measured by freezing during fear-conditioning training and context re-exposure). These phenotypes are relevant to multiple nonmotor symptoms of $\mathrm{PD}$ and are known to be under noradrenergic control. Sleep disturbances are one of the most common complaints of PD patients, and patients who experience disturbed sleep appear to have greater LC asyn pathology than those who do not report sleep disturbances (Kalaitzakis et al., 2013). Anxiety is also a common complaint, as up to $60 \%$ of PD patients report experiencing anxiety (Chaudhuri and Schapira, 2009; Lin et al., 2015). Importantly, $D B H$-hSNCA mice did not display changes in the number or speed of ambulations relative to nTg mice at any age examined, ruling out a general locomotor abnormality that has been 
observed in more ubiquitous asyn overexpression mice (Giasson et al., 2002; Fleming et al., 2004; Graham and Sidhu, 2010). Reducing DA specifically in DA neurons causes motor, but not most nonmotor, deficits in mice, which further indicates that these symptoms arise from alterations in distinct neurotransmitter systems (Jiang et al., 2020). In fact, the increased sleep latency observed in Tg animals was normalized by blocking $\alpha 1$ - and $\beta$-adrenergic receptors, which suggests that the behavioral phenotype is because of enhanced noradrenergic neurotransmission. The link between LC degeneration and nonmotor symptoms has always presented something of a paradox. For example, it is well established over many decades of both human and animal research that NE transmission is anxiogenic. Hypothetically, LC degeneration should lead to a loss of noradrenergic innervation and decreased tissue levels of NE, which should suppress, rather than facilitate, anxiety. We have previously speculated that asyn pathology promotes LC hyperactivity and nonmotor symptoms during PD progression before the degeneration of noradrenergic neurons later in the disease (Weinshenker, 2018), and the present data support that idea. Indeed, the behavioral phenotypes we observed were most prominent at 14 months, while the degeneration of LC fibers was not evident until 24 months, a time when behavioral abnormalities abated. There are several potential mechanisms by which increases in human asyn may be affecting the LC-NE system (Fig. 11). TH protein was increased in 3-and 14-month-old $\mathrm{Tg}$ mice, which is when behavioral phenotypes consistent with NE overactivity emerged. Because TH is the ratelimiting enzyme in NE production, this may reflect increased NE synthetic capacity, although the relevance is not clear because we did not detect differences in tissue NE content. Human wildtype asyn has been reported to increase the size, and delay the closing, of the vesicular fusion pore, allowing more neurotransmitter to spill into the extracellular space (Larsen et al., 2006; Logan et al., 2017). In addition, viral-mediated overexpression of A53T mutant asyn in LC neurons causes increased firing rate (Henrich et al., 2018). Alternatively, if human asyn expression is negatively impacting LC neuron health as suggested by the presence of asyn oligomers and the loss of hippocampal LC fibers at 24 months, there may be compensatory increases in neuronal activity. Chemical lesioning of LC neurons transiently increases NE neurotransmission by increasing neuronal firing frequency and activity patterns (Szot et al., 2016). Future studies directly examining LC neuron firing and NE release, as well as testing the ability of adrenergic antagonists to reverse other phenotypes beyond sleep latency in the DBH-hSNCA mice, will be necessary to identify the mechanism in play here.

LC neurons are among the first affected in PD, and the features of $D B H$-hSNCA mice may represent early pathology and nonmotor components of PD that provide insight into the functional impact of human asyn expression in LC neurons during aging. Importantly, our data suggest that the overexpression of wild-type human asyn and formation of oligomers alone is sufficient for the LC dysfunction, fiber degeneration, and behavioral deficits we observed, while asyn pSer129 inclusions are not required for these phenotypes. The notion that oligomeric asyn may be sufficient to change cellular function and behavior is supported by evidence from previously developed transgenic asyn rodent models that develop behavioral changes in the absence of asyn pSer129-positive inclusions (Tofaris et al., 2006; Janezic et al., 2013; Bengoa-Vergniory et al., 2017, 2020). Additionally, studies involving exposure to environmental factors that synergize with asyn expression to influence the risk of PD will likely elucidate the genetic and environmental interactions that contribute to LC involvement in the preclinical premotor stages of PD, as well as the impact of LC degeneration on the trajectory of $\mathrm{PD}$ pathogenesis.

\section{References}

Abbott RD, Ross GW, White LR, Tanner CM, Masaki KH, Nelson JS, Curb JD, Petrovitch H (2005) Excessive daytime sleepiness and subsequent development of Parkinson disease. Neurology 65:1442-1446.

Baekelandt V, Claeys A, Eggermont K, Lauwers E, De Strooper B, Nuttin B, Debyser Z (2002) Characterization of lentiviral vector-mediated gene transfer in adult mouse brain. Hum Gene Ther 13:841-853.

Bengoa-Vergniory N, Roberts RF, Wade-Martins R, Alegre-Abarrategui J (2017) Alpha-synuclein oligomers: a new hope. Acta Neuropathol 134:819-838.

Bengoa-Vergniory N, Faggiani E, Ramos-Gonzalez P, Kirkiz E, ConnorRobson N, Brown LV, Siddique I, Li Z, Vingill S, Cioroch M, Cavaliere F, Threlfell S, Roberts B, Schrader T, Klärner F-G, Cragg S, Dehay B,Bitan G,Matute C,Bezard E et al. (2020) CLR01 protects dopaminergic neurons in vitro and in vivo in human neurons and mouse models of Parkinson's. Nat Commun, in press.

Bharani KL, Derex R, Granholm AC, Ledreux A (2017) A noradrenergic lesion aggravates the effects of systemic inflammation on the hippocampus of aged rats. PLoS One 12:e0189821.

Braak E, Sandmann-Keil D, Rüb U, Gai WP, de Vos RA, Steur EN, Arai K, Braak H (2001) Alpha-synuclein immunopositive Parkinson's diseaserelated inclusion bodies in lower brain stem nuclei. Acta Neuropathol 101:195-201.

Britton DR, Britton KT (1981) A sensitive open field measure of anxiolytic drug activity. Pharmacol Biochem Behav 15:577-582.

Brunnström H, Friberg N, Lindberg E, Englund E (2011) Differential degeneration of the locus coeruleus in dementia subtypes. Clin Neuropathol 30:104-110.

Butkovich LM, Houser MC, Tansey MG (2018) $\alpha$-Synuclein and noradrenergic modulation of immune cells in Parkinson's disease pathogenesis. Front Neurosci 12:626.

Carter ME, Yizhar O, Chikahisa S, Nguyen H, Adamantidis A, Nishino S, Deisseroth K, de Lecea L (2010) Tuning arousal with optogenetic modulation of locus coeruleus neurons. Nat Neurosci 13:1526-1533.

Chalermpalanupap T, Schroeder JP, Rorabaugh JM, Liles LC, Lah JJ, Levey AI, Weinshenker D (2018) Locus coeruleus ablation exacerbates cognitive deficits, neuropathology, and lethality in P301S tau transgenic mice. J Neurosci 38:74-92.

Chartier-Harlin M-C, Kachergus J, Roumier C, Mouroux V, Douay X, Lincoln S, Levecque C, Larvor L, Andrieux J, Hulihan M, Waucquier N, Defebvre L, Amouyel P, Farrer M, Destée A (2004) Alpha-synuclein locus duplication as a cause of familial Parkinson's disease. Lancet 364:11671169.

Chaudhuri KR, Schapira AH (2009) Non-motor symptoms of Parkinson's disease: dopaminergic pathophysiology and treatment. Lancet Neurol 8:464-474.

Chen X, Huddleston DE, Langley J, Ahn S, Barnum CJ, Factor SA, Levey AI, Hu X (2014) Simultaneous imaging of locus coeruleus and substantia nigra with a quantitative neuromelanin MRI approach. Magn Reson Imaging 32:1301-1306.

Chui HC, Mortimer JA, Slager U, Zarow C, Bondareff W, Webster DD (1986) Pathologic correlates of dementia in Parkinson's disease. Arch Neurol 43:991-995.

Cubells JF, Schroeder JP, Barrie ES, Manvich DF, Sadee W, Berg T, Mercer K, Stowe TA, Liles LC, Squires KE, Mezher A, Curtin P, Perdomo DL, Szot P, Weinshenker D (2016) Human bacterial artificial chromosome (BAC) transgenesis fully rescues noradrenergic function in dopamine $\beta$-hydroxylase knockout mice. PLoS One 11:e0154864.

de Sousa Rodrigues ME, Bekhbat M, Houser MC, Chang J, Walker DI, Jones DP, Oller do Nascimento CMP, Barnum CJ, Tansey MG (2017) Chronic psychological stress and high-fat high-fructose diet disrupt metabolic and inflammatory gene networks in the brain, liver, and gut and promote behavioral deficits in mice. Brain Behav Immun 59:158-172.

Delenclos M, Faroqi AH, Yue M, Kurti A, Castanedes-Casey M, Rousseau L, Phillips V, Dickson DW, Fryer JD, McLean PJ (2017) Neonatal AAV delivery of alpha-synuclein induces pathology in the adult mouse brain. Acta Neuropathol Commun 5:51. 
den Hartog JW, Bethlem J (1960) The distribution of Lewy bodies in the central and autonomic nervous systems in idiopathic paralysis agitans. J Neurol Neurosurg Psychiatry 23:283-290.

Devauges V, Sara SJ (1991) Memory retrieval enhancement by locus coeruleus stimulation: evidence for mediation by beta-receptors. Behav Brain Res 43:93-97.

Duffy S, MacVicar BA (1995) Adrenergic calcium signaling in astrocyte networks within the hippocampal slice. J Neurosci 15:5535-5550.

Eng LF, Ghirnikar RS (1994) GFAP and astrogliosis. Brain Pathol 4:229-237.

Fahrig T (1993) Receptor subtype involved and mechanism of norepinephrine-induced stimulation of glutamate uptake into primary cultures of rat brain astrocytes. Glia 7:212-218.

Fearnley JM, Lees AJ (1991) Ageing and Parkinson's disease: substantia nigra regional selectivity. Brain 114:2283-2301.

Ferese R, Modugno N, Campopiano R, Santilli M, Zampatti S, Giardina E, Nardone A, Postorivo D, Fornai F, Novelli G, Romoli E, Ruggieri S, Gambardella S (2015) Four copies of SNCA responsible for autosomal dominant Parkinson's disease in two Italian siblings. Parkinsons Dis 2015:546462.

Fleming SM, Salcedo J, Fernagut PO, Rockenstein E, Masliah E, Levine MS, Chesselet MF (2004) Early and progressive sensorimotor anomalies in mice overexpressing wild-type human $\alpha$-synuclein. J Neurosci 24:94349440.

Fujita H, Tanaka J, Maeda N, Sakanaka M (1998) Adrenergic agonists suppress the proliferation of microglia through beta 2-adrenergic receptor. Neurosci Lett 242:37-40.

Fujiwara H, Hasegawa M, Dohmae N, Kawashima A, Masliah E, Goldberg MS, Shen J, Takio K, Iwatsubo T (2002) alpha-Synuclein is phosphorylated in synucleinopathy lesions. Nat Cell Biol 4:160-164.

Gerhard A, Pavese N, Hotton G, Turkheimer F, Es M, Hammers A, Eggert K, Oertel W, Banati RB, Brooks DJ (2006) In vivo imaging of microglial activation with $[11 \mathrm{C}](\mathrm{R})-\mathrm{PK} 11195$ PET in idiopathic Parkinson's disease. Neurobiol Dis 21:404-412.

German DC, Manaye KF, White CL 3rd, Woodward DJ, McIntire DD, Smith WK, Kalaria RN, Mann DM (1992) Disease-specific patterns of locus coeruleus cell loss. Ann Neurol 32:667-676.

Giasson BI, Duda JE, Quinn SM, Zhang B, Trojanowski JQ, Lee VM (2002) Neuronal alpha-synucleinopathy with severe movement disorder in mice expressing A53T human alpha-synuclein. Neuron 34:521-533.

Gonera EG, van't Hof M, Berger HJ, van Weel C, Horstink MW (1997) Symptoms and duration of the prodromal phase in Parkinson's disease. Mov Disord 12:871-876.

Graham DR, Sidhu A (2010) Mice expressing the A53T mutant form of human alpha-synuclein exhibit hyperactivity and reduced anxiety-like behavior. J Neurosci Res 88:1777-1783.

Grenhoff J, Nisell M, Ferré S, Aston-Jones G, Svensson TH (1993) Noradrenergic modulation of midbrain dopamine cell firing elicited by stimulation of the locus coeruleus in the rat. J Neural Transm Gen Sect 93:11-25.

Gyoneva S, Traynelis SF (2013) Norepinephrine modulates the motility of resting and activated microglia via different adrenergic receptors. J Biol Chem 288:15291-15302.

Halliday GM, Li YW, Blumbergs PC, Joh TH, Cotton RG, Howe PR, Blessing WW, Geffen LB (1990) Neuropathology of immunohistochemically identified brainstem neurons in Parkinson's disease. Ann Neurol 27:373-385.

Hansen C, Björklund T, Petit GH, Lundblad M, Murmu RP, Brundin P, Li JY (2013) A novel $\alpha$-synuclein-GFP mouse model displays progressive motor impairment, olfactory dysfunction and accumulation of $\alpha$-synuclein-GFP. Neurobiol Dis 56:145-155.

Haycock JW (1993) Multiple signaling pathways in bovine chromaffin cells regulate tyrosine hydroxylase phosphorylation at Ser19, Ser31, and Ser40. Neurochem Res 18:15-26.

Heneka MT, Nadrigny F, Regen T, Martinez-Hernandez A, DumitrescuOzimek L, Terwel D, Jardanhazi-Kurutz D, Walter J, Kirchhoff F, Hanisch UK, Kummer MP (2010) Locus coeruleus controls Alzheimer's disease pathology by modulating microglial functions through norepinephrine. Proc Natl Acad Sci U S A 107:6058-6063.

Henrich MT, Geibl FF, Lee B, Chiu WH, Koprich JB, Brotchie JM, Timmermann L, Decher N, Matschke LA, Oertel WH (2018) A53T- $\alpha$-synuclein overexpression in murine locus coeruleus induces Parkinson's disease-like pathology in neurons and glia. Acta Neuropathol Commun 6:39.
Hirsch E, Graybiel AM, Agid YA (1988) Melanized dopaminergic neurons are differentially susceptible to degeneration in Parkinson's disease. Nature 334:345-348.

Hobson JA, McCarley RW, Wyzinski PW (1975) Sleep cycle oscillation: reciprocal discharge by two brainstem neuronal groups. Science 189:55-58.

Hornykiewicz O (1998) Biochemical aspects of Parkinson's disease. Neurology 51:S2-S9.

Hunsley MS, Palmiter RD (2004) Altered sleep latency and arousal regulation in mice lacking norepinephrine. Pharmacol Biochem Behav 78:765-773.

Ip CW, Klaus LC, Karikari AA, Visanji NP, Brotchie JM, Lang AE, Volkmann J, Koprich JB (2017) AAV1/2-induced overexpression of A53T- $\alpha$-synuclein in the substantia nigra results in degeneration of the nigrostriatal system with Lewy-like pathology and motor impairment: a new mouse model for Parkinson's disease. Acta Neuropathol Commun 5:11.

Iversen LL, Rossor MN, Reynolds GP, Hills R, Roth M, Mountjoy CQ, Foote SL, Morrison JH, Bloom FE (1983) Loss of pigmented dopamine$\beta$-hydroxylase positive cells from locus coeruleus in senile dementia of Alzheimer's type. Neurosci Lett 39:95-100.

Janezic S, Threlfell S, Dodson PD, Dowie MJ, Taylor TN, Potgieter D, Parkkinen L, Senior SL, Anwar S, Ryan B, Deltheil T, Kosillo P, Cioroch M, Wagner K, Ansorge O, Bannerman DM, Bolam JP, Magill PJ, Cragg SJ, Wade-Martins R (2013) Deficits in dopaminergic transmission precede neuron loss and dysfunction in a new Parkinson model. Proc Natl Acad Sci U S A 110:E4016-E4025.

Jiang S, Berger S, Hu Y, Bartsch D, Tian Y (2020) Alterations of the motor and olfactory functions related to Parkinson's disease in transgenic mice with a VMAT2-deficiency in dopaminergic neurons. Front Neurosci 14:356.

Joers V, Dilley K, Rahman S, Jones C, Shultz J, Simmons H, Emborg ME (2014) Cardiac sympathetic denervation in 6-OHDA-treated nonhuman primates. PLoS One 9:e104850.

Johnson JD, Zimomra ZR, Stewart LT (2013) Beta-adrenergic receptor activation primes microglia cytokine production. J Neuroimmunol 254:161164.

Kalaitzakis ME, Gentleman SM, Pearce RK (2013) Disturbed sleep in Parkinson's disease: anatomical and pathological correlates. Neuropathol Appl Neurobiol 39:644-653.

Keren NI, Taheri S, Vazey EM, Morgan PS, Granholm AC, Aston-Jones GS, Eckert MA (2015) Histologic validation of locus coeruleus MRI contrast in post-mortem tissue. Neuroimage 113:235-245.

Kilbourn MR, Sherman P, Abbott LC (1998) Reduced MPTP neurotoxicity in striatum of the mutant mouse tottering. Synapse 30:205-210.

Kim YS, Joh TH (2006) Microglia, major player in the brain inflammation: their roles in the pathogenesis of Parkinson's disease. Exp Mol Med 38:333-347.

Kirik D, Rosenblad C, Burger C, Lundberg C, Johansen TE, Muzyczka N, Mandel RJ, Björklund A (2002) Parkinson-like neurodegeneration induced by targeted overexpression of $\alpha$-synuclein in the nigrostriatal system. J Neurosci 22:2780-2791.

Koprich JB, Johnston TH, Reyes MG, Sun X, Brotchie JM (2010) Expression of human A53T alpha-synuclein in the rat substantia nigra using a novel AAV1/2 vector produces a rapidly evolving pathology with protein aggregation, dystrophic neurite architecture and nigrostriatal degeneration with potential to model the pathology of Parkinson's disease. Mol Neurodegener 5:43.

Kreiner G, Rafa-Zabłocka K, Barut J, Chmielarz P, Kot M, Bagińska M, Parlato R, Daniel WA, Nalepa I (2019) Stimulation of noradrenergic transmission by reboxetine is beneficial for a mouse model of progressive parkinsonism. Sci Rep 9:5262.

Kumer SC, Vrana KE (1996) Intricate regulation of tyrosine hydroxylase activity and gene expression. J Neurochem 67:443-462.

Larsen KE, Schmitz Y, Troyer MD, Mosharov E, Dietrich P, Quazi AZ, Savalle M, Nemani V, Chaudhry FA, Edwards RH, Stefanis L, Sulzer D (2006) $\alpha$-Synuclein overexpression in PC12 and chromaffin cells impairs catecholamine release by interfering with a late step in exocytosis. J Neurosci 26:11915-11922.

Lategan AJ, Marien MR, Colpaert FC (1990) Effects of locus coeruleus lesions on the release of endogenous dopamine in the rat nucleus accumbens and caudate nucleus as determined by intracerebral microdialysis. Brain Res 523:134-138. 
Leenders KL, Salmon EP, Tyrrell P, Perani D, Brooks DJ, Sager H, Jones T, Marsden CD, Frackowiak RS (1990) The nigrostriatal dopaminergic system assessed in vivo by positron emission tomography in healthy volunteer subjects and patients with Parkinson's disease. Arch Neurol 47:12901298.

Levitt M, Spector S, Sjoerdsma A, Udenfriend S (1965) Elucidation of the rate-limiting step in norepinephrine biosynthesis in the perfused guineapig heart. J Pharmacol Exp Ther 148:1-8.

Lin CH, Lin JW, Liu YC, Chang CH, Wu RM (2015) Risk of Parkinson's disease following anxiety disorders: a nationwide population-based cohort study. Eur J Neurol 22:1280-1287.

Lloyd GM, Trejo-Lopez JA, Xia Y, McFarland KN, Lincoln SJ, Ertekin-Taner N, Giasson BI, Yachnis AT, Prokop S (2020) Prominent amyloid plaque pathology and cerebral amyloid angiopathy in APP V717I (London) carrier-phenotypic variability in autosomal dominant Alzheimer's disease. Acta Neuropathol Commun 8:31.

Logan T, Bendor J, Toupin C, Thorn K, Edwards RH (2017) $\alpha$-Synuclein promotes dilation of the exocytotic fusion pore. Nat Neurosci 20:681689.

Lustberg D, Iannitelli AF, Tillage RP, Pruitt M, Liles LC, Weinshenker D (2020) Central norepinephrine transmission is required for stressinduced repetitive behavior in two rodent models of obsessive-compulsive disorder. Psychopharmacology (Berl) 237:1973-1987.

Mann JJ, Stanley M, Kaplan RD, Sweeney J, Neophytides A (1983) Central catecholamine metabolism in vivo and the cognitive and motor deficits in Parkinson's disease. J Neurol Neurosurg Psychiatry 46:905-910.

Maskri L, Zhu X, Fritzen S, Kühn K, Ullmer C, Engels P, Andriske M, Stichel CC, Lübbert H (2004) Influence of different promoters on the expression pattern of mutated human alpha-synuclein in transgenic mice. Neurodegener Dis 1:255-265.

Masliah E, Rockenstein E, Veinbergs I, Mallory M, Hashimoto M, Takeda A, Sagara Y, Sisk A, Mucke L (2000) Dopaminergic loss and inclusion body formation in alpha-synuclein mice: implications for neurodegenerative disorders. Science 287:1265-1269.

Mavridis M, Degryse AD, Lategan AJ, Marien MR, Colpaert FC (1991) Effects of locus coeruleus lesions on parkinsonian signs, striatal dopamine and substantia nigra cell loss after 1-methyl-4-phenyl-1,2,3,6-tetrahydropyridine in monkeys: a possible role for the locus coeruleus in the progression of Parkinson's disease. Neuroscience 41:507-523.

McCall JG, Al-Hasani R, Siuda ER, Hong DY, Norris AJ, Ford CP, Bruchas MR (2015) CRH engagement of the locus coeruleus noradrenergic system mediates stress-induced anxiety. Neuron 87:605-620.

McGeer PL, Itagaki S, Boyes BE, McGeer EG (1988) Reactive microglia are positive for HLA-DR in the substantia nigra of Parkinson's and Alzheimer's disease brains. Neurology 38:1285-1291.

Murchison CF, Zhang XY, Zhang WP, Ouyang M, Lee A, Thomas SA (2004) A distinct role for norepinephrine in memory retrieval. Cell 117:131-143.

Niu H, Shen L, Li T, Ren C, Ding S, Wang L, Zhang Z, Liu X, Zhang Q, Geng D, Wu X, Li H (2018) Alpha-synuclein overexpression in the olfactory bulb initiates prodromal symptoms and pathology of Parkinson's disease. Transl Neurodegener 7:25.

Norris JG, Benveniste EN (1993) Interleukin-6 production by astrocytes: induction by the neurotransmitter norepinephrine. J Neuroimmunol 45:137-145

Paukert M, Agarwal A, Cha J, Doze VA, Kang JU, Bergles DE (2014) Norepinephrine controls astroglial responsiveness to local circuit activity. Neuron 82:1263-1270.

Pavese N, Rivero-Bosch M, Lewis SJ, Whone AL, Brooks DJ (2011) Progression of monoaminergic dysfunction in Parkinson's disease: a longitudinal 18F-dopa PET study. Neuroimage 56:1463-1468.

Phillips RG, LeDoux JE (1992) Differential contribution of amygdala and hippocampus to cued and contextual fear conditioning. Behav Neurosci 106:274-285.

Pifl C, Kish SJ, Hornykiewicz O (2012) Thalamic noradrenaline in Parkinson's disease: deficits suggest role in motor and non-motor symptoms. Mov Disord 27:1618-1624.

Porter-Stransky KA, Centanni SW, Karne SL, Odil LM, Fekir S, Wong JC, Jerome C, Mitchell HA, Escayg A, Pedersen NP, Winder DG, Mitrano DA, Weinshenker D (2019) Noradrenergic transmission at alpha1-adrenergic receptors in the ventral periaqueductal gray modulates arousal. Biol Psychiatry 85:237-247.
Remy P, Doder M, Lees A, Turjanski N, Brooks D (2005) Depression in Parkinson's disease: loss of dopamine and noradrenaline innervation in the limbic system. Brain 128:1314-1322.

Rinaman L (2011) Hindbrain noradrenergic A2 neurons: diverse roles in autonomic, endocrine, cognitive, and behavioral functions. Am J Physiol Regul Integr Comp Physiol 300:R222-235.

Roberts RF, Wade-Martins R, Alegre-Abarrategui J (2015) Direct visualization of alpha-synuclein oligomers reveals previously undetected pathology in Parkinson's disease brain. Brain 138:1642-1657.

Rommelfanger KS, Weinshenker D (2007) Norepinephrine: the redheaded stepchild of Parkinson's disease. Biochem Pharmacol 74:177-190.

Rommelfanger KS, Weinshenker D, Miller GW (2004) Reduced MPTP toxicity in noradrenaline transporter knockout mice. J Neurochem 91:11161124.

Rommelfanger KS, Edwards GL, Freeman KG, Liles LC, Miller GW, Weinshenker D (2007) Norepinephrine loss produces more profound motor deficits than MPTP treatment in mice. Proc Natl Acad Sci U S A 104:13804-13809.

Rorabaugh JM, Chalermpalanupap T, Botz-Zapp CA, Fu VM, Lembeck NA, Cohen RM, Weinshenker D (2017) Chemogenetic locus coeruleus activation restores reversal learning in a rat model of Alzheimer's disease. Brain 140:3023-3038.

Ross GW, Petrovitch H, Abbott RD, Tanner CM, Popper J, Masaki K, Launer L, White LR (2008) Association of olfactory dysfunction with risk for future Parkinson's disease. Ann Neurol 63:167-173.

Rutherford NJ, Brooks M, Giasson BI (2016) Novel antibodies to phosphorylated $\alpha$-synuclein serine 129 and NFL serine 473 demonstrate the close molecular homology of these epitopes. Acta Neuropathol Commun 4:80.

Sampson TR, Debelius JW, Thron T, Janssen S, Shastri GG, Ilhan ZE, Challis C, Schretter CE, Rocha S, Gradinaru V, Chesselet MF, Keshavarzian A, Shannon KM, Krajmalnik-Brown R, Wittung-Stafshede P, Knight R, Mazmanian SK (2016) Gut microbiota regulate motor deficits and neuroinflammation in a model of Parkinson's disease. Cell 167:1469-1480. e12.

Sawamoto K, Nakao N, Kobayashi K, Matsushita N, Takahashi H, Kakishita K, Yamamoto A, Yoshizaki T, Terashima T, Murakami F, Itakura T, Okano H (2001) Visualization, direct isolation, and transplantation of midbrain dopaminergic neurons. Proc Natl Acad Sci U S A 98:64236428.

Schank JR, Ventura R, Puglisi-Allegra S, Alcaro A, Cole CD, Liles LC, Seeman P, Weinshenker D (2006) Dopamine beta-hydroxylase knockout mice have alterations in dopamine signaling and are hypersensitive to cocaine. Neuropsychopharmacology 31:2221-2230.

Schell H, Hasegawa T, Neumann M, Kahle PJ (2009) Nuclear and neuritic distribution of serine-129 phosphorylated alpha-synuclein in transgenic mice. Neuroscience 160:796-804.

Singleton AB, Farrer M, Johnson J, Singleton A, Hague S, Kachergus J, Hulihan M, Peuralinna T, Dutra A, Nussbaum R, Lincoln S, Crawley A, Hanson M, Maraganore D, Adler C, Cookson MR, Muenter M, Baptista M, Miller D, Blancato J, Hardy J, Gwinn-Hardy K (2003) $\alpha$-Synuclein locus triplication causes Parkinson's disease. Science 302:841.

Song CH, Fan X, Exeter CJ, Hess EJ, Jinnah HA (2012) Functional analysis of dopaminergic systems in a DYT1 knock-in mouse model of dystonia. Neurobiol Dis 48:66-78.

Song S, Jiang L, Oyarzabal EA, Wilson B, Li Z, Shih YI, Wang Q, Hong JS (2019) Loss of brain norepinephrine elicits neuroinflammation-mediated oxidative injury and selective caudo-rostral neurodegeneration. Mol Neurobiol 56:2653-2669.

Sotiriou E, Vassilatis DK, Vila M, Stefanis L (2010) Selective noradrenergic vulnerability in alpha-synuclein transgenic mice. Neurobiol Aging 31:2103-2114.

Spillantini MG, Schmidt ML, Lee VM, Trojanowski JQ, Jakes R, Goedert M (1997) Alpha-synuclein in Lewy bodies. Nature 388:839-840.

Srinivasan J, Schmidt WJ (2003) Potentiation of parkinsonian symptoms by depletion of locus coeruleus noradrenaline in 6-hydroxydopamineinduced partial degeneration of substantia nigra in rats. Eur J Neurosci 17:2586-2592.

Szot P, Franklin A, Miguelez C, Wang Y, Vidaurrazaga I, Ugedo L, Sikkema C, Wilkinson CW, Raskind MA (2016) Depressive-like behavior observed with a minimal loss of locus coeruleus (LC) neurons following administration of 6-hydroxydopamine is associated with 
electrophysiological changes and reversed with precursors of norepinephrine. Neuropharmacology 101:76-86.

Tansey MG, Goldberg MS (2010) Neuroinflammation in Parkinson's disease: its role in neuronal death and implications for therapeutic intervention. Neurobiol Dis 37:510-518.

Tofaris GK, Garcia Reitböck P, Humby T, Lambourne SL, O'Connell M, Ghetti B, Gossage H, Emson PC, Wilkinson LS, Goedert M, Spillantini MG (2006) Pathological changes in dopaminergic nerve cells of the substantia nigra and olfactory bulb in mice transgenic for truncated human $\alpha$-synuclein(1-120): implications for Lewy body disorders. J Neurosci 26:3942-3950

Tong J, Hornykiewicz O, Kish SJ (2006) Inverse relationship between brain noradrenaline level and dopamine loss in Parkinson disease: a possible neuroprotective role for noradrenaline. Arch Neurol 63:1724-1728.

Valentino RJ, Van Bockstaele E (2008) Convergent regulation of locus coeruleus activity as an adaptive response to stress. Eur J Pharmacol 583:194203.
Vazey EM, Aston-Jones G (2014) Designer receptor manipulations reveal a role of the locus coeruleus noradrenergic system in isoflurane general anesthesia. Proc Natl Acad Sci U S A 111:3859-3864.

Wakamatsu M, Ishii A, Ukai Y, Sakagami J, Iwata S, Ono M, Matsumoto K, Nakamura A, Tada N, Kobayashi K, Iwatsubo T, Yoshimoto M (2007) Accumulation of phosphorylated alpha-synuclein in dopaminergic neurons of transgenic mice that express human alpha-synuclein. J Neurosci Res 85:1819-1825.

Weinshenker D (2018) Long road to ruin: noradrenergic dysfunction in neurodegenerative disease. Trends Neurosci 41:211-223.

Yao N, Wu Y, Zhou Y, Ju L, Liu Y, Ju R, Duan D, Xu Q (2015) Lesion of the locus coeruleus aggravates dopaminergic neuron degeneration by modulating microglial function in mouse models of Parkinson's disease. Brain Res 1625:255-274.

Zarow C, Lyness SA, Mortimer JA, Chui HC (2003) Neuronal loss is greater in the locus coeruleus than nucleus basalis and substantia nigra in Alzheimer and Parkinson diseases. Arch Neurol 60:337-341. 